\title{
A dynamic model for spread of livestock-associated methicillin-resistant Staphylococcus aureus on a pig farm, incorporating bacterial load and human exposure through air
}

Sørensen, Anna Irene Vedel; Hansen, Julie Elvekjær; Halasa, Tariq

Published in:

Journal of Theoretical Biology

Link to article, DOI:

10.1016/j.jtbi.2020.110402

Publication date:

2020

Document Version

Peer reviewed version

Link back to DTU Orbit

Citation (APA):

Sørensen, A. I. V., Hansen, J. E., \& Halasa, T. (2020). A dynamic model for spread of livestock-associated methicillin-resistant Staphylococcus aureus on a pig farm, incorporating bacterial load and human exposure through air. Journal of Theoretical Biology, 505, [110402]. https://doi.org/10.1016/j.jtbi.2020.110402

\section{General rights}

Copyright and moral rights for the publications made accessible in the public portal are retained by the authors and/or other copyright owners and it is a condition of accessing publications that users recognise and abide by the legal requirements associated with these rights.

- Users may download and print one copy of any publication from the public portal for the purpose of private study or research.

- You may not further distribute the material or use it for any profit-making activity or commercial gain

- You may freely distribute the URL identifying the publication in the public portal 


\section{Journal Pre-proofs}

A dynamic model for spread of livestock-associated methicillin-resistant

Staphylococcus aureus on a pig farm, incorporating bacterial load and human exposure through air

Anna Irene Vedel Sørensen, Julie Elvekjær Hansen, Tariq Halasa

PII:

S0022-5193(20)30257-5

DOI:

https://doi.org/10.1016/j.jtbi.2020.110402

Reference:

YJTBI 110402

To appear in:

Journal of Theoretical Biology

Received Date:

5 December 2019

Revised Date:

11 April 2020

Accepted Date:

5 July 2020

Please cite this article as: A. Irene Vedel Sørensen, J. Elvekjær Hansen, T. Halasa, A dynamic model for spread of livestock-associated methicillin-resistant Staphylococcus aureus on a pig farm, incorporating bacterial load and human exposure through air, Journal of Theoretical Biology (2020), doi: https://doi.org/10.1016/j.jtbi. 2020.110402

This is a PDF file of an article that has undergone enhancements after acceptance, such as the addition of a cover page and metadata, and formatting for readability, but it is not yet the definitive version of record. This version will undergo additional copyediting, typesetting and review before it is published in its final form, but we are providing this version to give early visibility of the article. Please note that, during the production process, errors may be discovered which could affect the content, and all legal disclaimers that apply to the journal pertain.

(C) 2020 Published by Elsevier Ltd. 
3 A dynamic model for spread of livestock-associated methicillin-resistant

8 Anna Irene Vedel Sørensena,b*, Julie Elvekjær Hansen ${ }^{b, c} \&$ Tariq Halasaa,b.

9 a. Present address: Department of Veterinary and Animal Sciences, Copenhagen University,

10 Grønnegårdsvej 8, DK-1870 Frederiksberg, Denmark. Denmark. Lyngby, Denmark. 
Keywords: Mechanistic modelling; transmission of infectious diseases; veterinary epidemiology; predicting effect of interventions.

\begin{abstract}
Livestock-associated methicillin-resistant Staphylococcus aureus (LA-MRSA) is widely distributed in the pig population in many countries, where its presence is undesirable, because as an opportunistic human pathogen, it poses a threat to human health.
\end{abstract}

At present, there is a lack of knowledge regarding successful methods for eradication of LA-MRSA on a pig farm, which does not involve emptying the farm and culling all pigs. Some studies have reported an association between levels of LA-MRSA in the barn air and LA-MRSA carriage among humans entering or working in the pig barns. Therefore, interventions that are able to reduce the amount of LA-MRSA carried by the pigs and/or the concentration of LA-MRSA in the barn air, might be highly relevant if aiming for reducing the spread of LA-MRSA into the general human population.

In the present study, an existing agent-based simulation model for spread of LA-MRSA within a pig herd was extended to also include LA-MRSA load and spread through air. This makes it possible to use the model for studying the air exposure to LA-MRSA for humans entering the pig barns. The model was used for simulating various types of interventions in contaminated herds.

At present quantitative data for nasal carriage of LA-MRSA in pigs are sparse, and many knowledge gaps regarding spread of LA-MRSA remain. Thus, our goal of building this model was not to provide exact values for risk reduction, but to avail a model that can be used for studying the effect of various types of interventions mechanistically, once more relevant data become available. Collection of more data on the influence of load is crucial for getting a better understanding of which possible interventions strategies, that might still have some potential in countries, where LA-MRSA has already spread to the majority of the pig population. 


\section{Introduction}

Occurrence of livestock-associated methicillin-resistant Staphylococcus aureus (LA-MRSA) in pig herds has been reported in most European countries (Crombé et al., 2013) in addition to Canada, USA, Australia and several countries in Asia (Chuang and Huang, 2015; Harper et al., 2010; Khanna et al., 2008; Sahibzada et al., 2017). LA-MRSA has rarely been identified as a source of disease in pigs, but presence of this bacterium is undesirable due to the risk of transmission into the human population. LA-MRSA is able to act as an opportunistic human pathogen and can cause a wide range of different conditions, including skin and soft tissue infections, pneumonia, joint infections and bacteraemia (Becker et al., 2015; Cuny et al., 2015).

On farms housing LA-MRSA positive animals, LA-MRSA has been isolated from various surfaces in the barn environment, as well as dust and air (Espinosa-Gongora et al., 2015; Feld et al., 2018; Friese et al., 2012; Madsen et al., 2018). The results of several studies have indicated that concentrations of LA-MRSA in the air within the barn units play an important role for transmission to humans working on the farm (Angen et al., 2017; Bos et al., 2016), as well as in relation to transmission between pigs (Rosen et al., 2018).

Currently, there is a lack of knowledge regarding successful methods for complete eradication of LA-MRSA on a farm, which does not involve culling of all animals. However, since an association between exposure levels in barn air and carriage in farmers and visitors have been demonstrated (Angen et al., 2017; Bos et al., 2016), it could be speculated that reducing the concentration of LA-MRSA in the barn air might be enough to actually decrease the risk of transmission to humans. This could either be a reduction in the load carried by each pig, or a reduction in the concentration of LA-MRSA in the barn air, e.g. through air washing and UV-irradiation (Schulz et al., 2013) or a general reduction in the presence of LA-MRSA in the surrounding environment, e.g. through use of a disinfectant (Espinosa-Gongora et al., 2013).

Results of simulations of spread of LA-MRSA between farms, have indicated that the within-herd prevalence influences spread of LA-MRSA between farms (Schulz et al., 2018), and thus one could speculate that reducing the load on infected farms might also be able to limit the spread of LA-MRSA between herds. 
In a previous study, various interventions against LA-MRSA was modelled mechanistically (Sørensen et al., 2018) using a previously published agent-based model for spread of LA-MRSA within a farrow-to-finish pig herd (Sørensen et al., 2017). However, this model did not take into account the potential influence of the amount of LA-MRSA carried by each pig on the pigs' ability to pass on LA-MRSA to other pigs. Further, the LA-MRSA concentration in the air was not modelled.

The objectives of the present study were to: 1) Extend an existing agent-based simulation model for spread of LA-MRSA within a pig herd to also include load and spread through air and thereby be able to assess exposure to LA-MRSA for humans entering the pig barns; 2) Use this model for simulating interventions in highly contaminated herds, and assess the effect of interventions on exposure through air. This can be interventions which: a) Reduces the prevalence of LA-MRSA shedding pigs, b) Are able to reduce the load of LA-MRSA carried by the pigs without necessarily reducing the prevalence of animals shedding LA-MRSA.

\section{Materials and methods}

\subsection{Model construction}

The model is based on a previously published model (Sørensen et al., 2017), which has been expanded by the incorporation of bacterial load levels and concentration of LA-MRSA in the air, as explained beneath. It is an agent-based stochastic mechanistic model with discrete time steps of one day each. The updated model was built in R version 3.5.2 - "Eggshell Igloo" (R Core team, 2015), and consists of a herd model and an epidemic model.

\subsubsection{Herd model}

The herd model describes a medium-sized Danish farrow-to-finish herd, which comprises approximately 500 sows and produces around 15,400 slaughter pigs annually. It was assumed that the production in the herd is running according to a batch production scheme (i.e all-in/all-out on section level) based on 21 sow 
batches with one week between each batch. In the model we assume that the cleaning and disinfection between each batch is perfect, i.e. there is no carry-over of LA-MRSA. The simulated farm consisted of five different barn units; the mating, gestation, farrowing, weaner and finisher unit, and each unit was separated into several sections housing one batch each (except the gestation unit, where loose housing was applied). Each section were housing a number of pens, where the number of pigs per pen depended on the type of unit (e.g. there were more pigs per pen in the weaner unit compared to in the finisher unit). It was assumed that gilts were bought from other herds and housed in the mating section upon arrival. Twostep nurse sows (foster dams) were used for excess piglets from big litters. The herd model also included insemination failure/re-insemination and death or removal of pigs. For further details on assumptions and parameters in the herd model, please see Sørensen et al., 2017.

\subsubsection{Epidemic model}

In the epidemic model used for spread of LA-MRSA, each pig can be in one of three different disease stages:

1) Susceptible (S), 2) Intermittent shedder (IS), or 3) Persistent shedder (PS). The model included different routes of transmission with individual transmission parameters for each route: 1) Transmission between pigs within the same pen, 2) Transmission between pigs in different pens within the same section, 3 ) Transmission between sections within the same barn unit, and 4) Transmission between barn units. In addition, there was a special parameter for transmission between sows and offspring on the day of farrowing, which was supposed to also represent perinatal transmission. It was assumed that whether or not a pig became a persistent shedder, depended on host-related factors as well as on the level of exposure (the prevalence of positive animals within the room). For intermittent shedders the duration of carriage used in the model ranged from 1 to 26 days and was based on the results obtained in a Dutch transmission study (Broens et al., 2012b). An overview of values and sources for transmission parameters is given in Appendix A. In the present model, load classes were implemented in the original model structure, in 
addition to an air reservoir for LA-MRSA. These modifications, as well as the data basis and assumptions behind these, are described in further details in section 2.1.3-2.1.4.

\subsubsection{Inclusion of bacterial load}

Due to the uncertainty related to the influence of load on infectiousness, the model were ran with three different parameterisations ( $A, B$ and $C$ ) and compared to the original framework and existing knowledge in order to assess, which parameterisation it made most sense to use. Load was included in the model as five or six different load classes (the number of classes depended on the parameterisation), where going one load class up was assumed to represent one 10-logarithmic unit increase in load, except for the lowest load class, L1 (table 1). This load class (L1) was introduced in order to be able to handle data that contained samples, which only tested positive, when using enrichment, and hence reflected very low levels of colonisation or contamination. The load in these samples were set to $0.5 *$ the assumed limit of detection for the method otherwise used for quantification, i.e. $5 \mathrm{CFU} / \mathrm{swab}$.

For calculation purposes, each pig was also assigned an exact load within the relevant interval (table 1). However, this was only used for modelling the concentration of LA-MRSA in the air, and did not influence transmission.

In a previous version of the model, which did not include load, all scenarios were simulated in triplicate using three different sets of transmission rates, in order to take the uncertainty associated with these into account. In the present study, one of these three sets of rates (based on Broens et al., 2012a), where batch treatment with beta-lactams and/or tetracyclines had been used, was chosen as the basis to be weighted depending on load in order to create the three new parameterisations.

To our best knowledge, there is currently no available evidence for how much or how little the LA-MRSA loads of pigs are influencing transmission of LA-MRSA between pigs. Therefore, the weightings of the different load classes in the three parameterisations of the model (table 1) were calibrated to make the 


\begin{tabular}{ccccc}
\hline Load class & $\begin{array}{c}\text { Interval for exact load } \\
\text { (CFU/swab) }\end{array}$ & \multicolumn{3}{c}{ Weighting factors for transmission rates } \\
\cline { 3 - 5 } & & A & B & C \\
\hline 1 & $5 ; 9$ & - & 0.25 & 0.50 \\
\hline 2 & $10 ; 99$ & 0.25 & 0.50 & 0.75 \\
\hline 3 & $100 ; 999$ & 0.50 & 1.00 & 1.00 \\
\hline 4 & $1000 ; 9999$ & 1.00 & 2.00 & 1.50 \\
\hline 5 & 10,$000 ; 99,999$ & 2.00 & 5.00 & 2.25 \\
\hline 6 & 100,$000 ; 999,999$ & 5.00 & 10.00 & 3.00 \\
\hline
\end{tabular}
of the weightings are listed in Appendix B, section B1.

\section{Table 1: Load classes and weighting used in the model}

\subsubsection{Load upon "infection"}

141 The initial load level upon "infection" was assumed to exhibit individual variation between pigs, but also to 142 somehow be related to the overall LA-MRSA load in the room, i.e. the shedder prevalence and load of the 143 other pigs present in the room. When using parameterisation $A$, the starting levels upon infection were 144 sampled from four different distributions ( $\mathrm{S} 1$ table), which all were based on data from the same study. In 145 that study, LA-MRSA loads on nasal swabs from 26 pigs in each of nine consecutive batches of weaners on one farm had been determined (234 animals in total) (Bækbo et al., 2018) (S1 fig.). On the day of birth,

147 piglets were assigned an initial load level that was sampled from a distribution, which depended on the 148 load carried by the dam (for details, please see table B1 in Appendix B).

149 Intermittent shedders (IS) were assumed to carry LA-MRSA in lower levels than persistent shedders (PS), 150 analogous to what has been reported in humans (Verhoeven et al., 2012). Thus, the load class for persistent 

shedders were always increased by one load class level, compared to the level initially sampled from the distribution.

When using parameterisation B and C, exact loads were sampled from pert-distributions ( $\mathrm{S} 2$ table) and then afterwards load classes were assigned accordingly.

\subsubsection{Development in the load during the shedding period}

It was assumed that during the shedding period, the nasal load carried by each pig fluctuates over time.

This is consistent with the results of longitudinal studies, where pigs changes status and/or level several times during the study period (Bangerter et al., 2016; Espinosa-Gongora et al., 2015), albeit there is a shortage of studies which involve actual quantification of LA-MRSA. However, the magnitude of change from day-to-day (if any) were sampled from a distribution, which was based on data from an observational study, where the same pigs had been tested on two successive days (Hansen et al., unpublished data). This was repeated twice with different pigs (number of animals tested per visit $=60$ ). The data was used on class level, and the day-to-day change in terms of classes (e.g. $0,+2,-1$ ) was used directly for creating a distribution to sample from in the model (S2 fig.).

\subsubsection{Transmission through air}

Research has indicated, that exposure to MRSA in the air might play an important role in spread of LAMRSA between pigs (Rosen et al., 2018) as well as in spread from pigs to humans (Angen et al., 2017; Bos et al., 2016). The association between the amount of LA-MRSA carried by the pigs and the concentration found in the air within pig barns is not well-described, since quantitative data for nasal load of LA-MRSA in pigs are sparse. In the present study, we utilised data, where a correlation between the mean concentration of MRSA in air within each barn room (two measurements) and mean nasal loads in the pigs within the same barn room was identified (combined data from Hansen, 2018 and Bækbo et al., 2018). This was based on air concentrations measured approximately $1.5 \mathrm{~m}$ above ground level using air filtration with 
a Sartorius sampler (for further method description, please see Hansen, 2018). In the model, we used the correlation between air concentrations and pig load directly for estimating the amount of bacteria that diffused from the pigs and into barn air. In parameterisation $A$, the association between nasal load in the pigs and load in the air was modelled based on load classes, whereas in B and C, it was estimated directly based on the assigned nasal load and the correlation with the air concentration (for further detail, please see Appendix B, section B.2). Transmission back and forth from air and to the pigs was in principle already included in the transmission rates used and to our best knowledge, at present no data that enables us to separate this type of contact from direct contact or contact by other means is available. In the present study, this route of transmission was therefore only indirectly included in the model, in the way that the concentration of LA-MRSA in the air was modelled separately, but the output was not used for anything other than assessing human exposure to LA-MRSA through air for those entering the pig barns.

\subsection{Model run}

All scenarios were run for a simulated time period of 6 years, consisting of a four-year burn-in period before introduction of LA-MRSA, followed by a two-year period to observe spread and consequences of simulated interventions. In most cases, only results from the first year after introduction were presented, since no further development of interest was observed. In all scenarios, it was assumed that LA-MRSA was introduced in the herd through purchase of one LA-MRSA shedding gilt. The effect of different introductions had already been assessed in a previous study (Sørensen et al., 2017).

Convergence of the new model was assessed by plotting the variance of the prevalence of LA-MRSA shedding pigs against the number of iterations ( $\mathrm{S} 3 \mathrm{fig}$.). Based on these results, it was decided that 250 iterations provided sufficient stability, and thus this number of iterations was used for all other simulation scenarios presented in this paper. 


\subsection{Sensitivity analysis}

201 Due to the uncertainty associated with the transmission parameters in the model, a process sensitivity 202 analysis was conducted in the form of the inclusion of three different parameterisations in the simulated 203 scenarios. A traditional sensitivity analysis including changes of some of the most central parameters had 204 already been conducted for the original model before the implementation of load (Sørensen et al., 2017). In 205 this analysis, duration of shedding and the assumed existence of persistent shedders were the most 206 influential factors, and therefore a sensitivity analysis including these two factors were repeated for the present model. This means that the duration of shedding was sampled from an alternative random PERT distribution (Most likely value: 18 days, range: 6-29 days), where the values were based on results obtained by Broens et al., 2012b. Regarding persistent shedders, it was assumed that these did not exist, and that all pigs just became intermittent shedders upon infection.

\subsection{Validation}

213 The model was mainly validated using the rationalism method, i.e. assessing whether the output changed as expected as a consequence of changes in the input parameters. Since quantitative data for the occurrence of LA-MRSA are sparse, most of the available data had already been used for parameterisation of the model, and thus could not be used for external validation. The load model was therefore mainly validated by comparing prevalence outputs to semi-quantitative data for pig load from a study that had not been used for parameterisation of the load-part of the model (Espinosa-Gongora et al., 2015). Additionally, 219 it was checked if the simulated air levels were within the same range as those reported in observational 220 studies (Angen et al., 2019; Hansen, 2018). 


\subsection{Interventions}

\subsubsection{Types of intervention scenarios}

In order to simulate the effect of different interventions on LA-MRSA exposure, two different types of interventions were simulated: 1) A direct reduction in transmission rates, e.g. to represent changes in antimicrobial consumption patterns, 2) A reduction in the load carried by each pig, which e.g. could represent use of a disinfectant powder. When simulating reductions in transmission rates, we investigated reductions to $10 \%-70 \%$ of the original transmission rates $(10,20,30,40,50,60$ and $70 \%$, but since the outputs changed gradually, in order to save space only results of the min., max. and median of these are presented). The $40 \%$ scenario was of particular interest, since the transmission rates in this scenario became almost equal to the rates estimated in an observational study (Broens et al., 2012) for when no beta-lactams or tetracyclines were used for treatment of the pigs.

\subsubsection{Implementation of interventions}

When the effect of different interventions were simulated, it was assumed that they were implemented either in: 1) A specific fraction of all pigs consisting of randomly selected pigs (e.g. 20\%), 2). All the pigs in one specific barn unit (e.g. the weaner unit).

Additionally, it varied, whether we assumed that interventions were: 1) Only initiated once as a single day initiative, or 2) Continuously applied every day until end of simulation.

It was assumed that all interventions were only implemented once that LA-MRSA had become fully established within the farm. In the simulations, the time needed to make sure that this had happened was set to 180 days after introduction of LA-MRSA on the farm, based on the results obtained in the scenarios without interventions. 
An overview table of the simulated interventions are available in Appendix $\mathrm{C}$.

\section{Results}

\subsection{Comparison of the three different parameterisations}

The weightings of load in the three different parameterisations of the model were calibrated to yield

A. Original (without load)

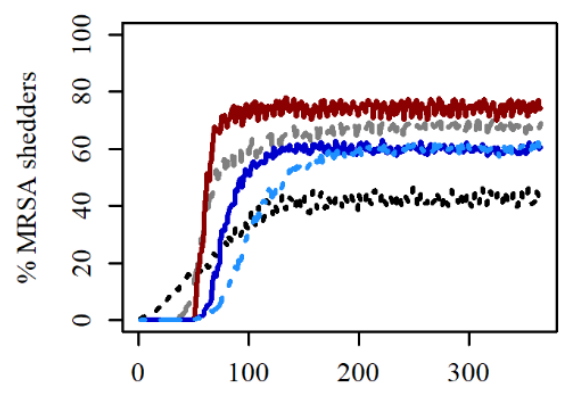

Days after first MRSA introduction

C. Load model - par. B

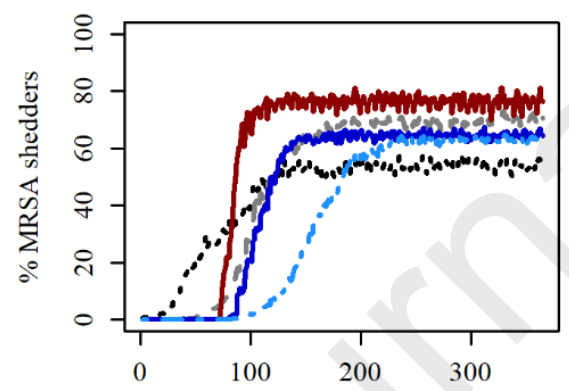

Days after first MRSA introduction
B. Load model - par. A

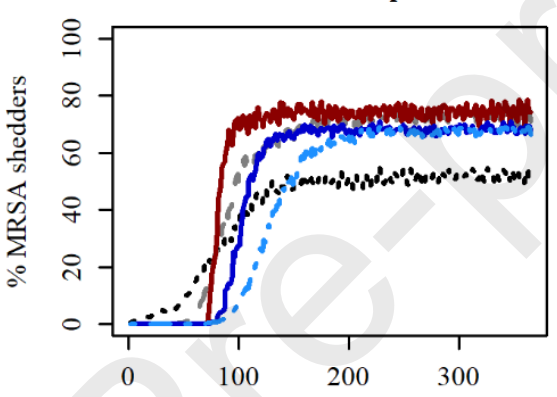

Days after first MRSA introduction

D. Load model - par. C

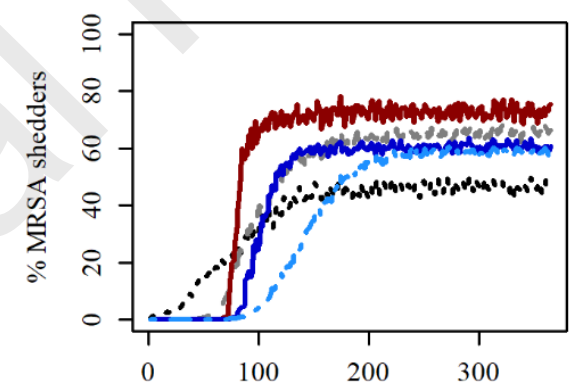

Days after first MRSA introduction

Fig. 1. The simulated development in the median prevalence of LA-MRSA shedders in the five different stable units following introduction by one intermittently shedding gilt, when using three different parameterisations of the model: A) The original model without load, B) Association between pig and air load modelled class wise (Parameterisation A), C) Continuous level used (Parameterisation B), D) Continuous level used (Parameterisation C). Mat = mating unit, Gest = gestation unit, Farr = farrowing unit, Wean $=$ weaning unit, Fini $=$ finisher unit. 
258 When comparing the development in the distribution of the different load classes among the pigs shedding

259 LA-MRSA over time (fig. 2), it is important to note, that parameterisation A does not contain the lowest

260 load class (L1), and generally yields much higher loads and a more even distribution among the load classes,

261 compared to the other two parameterisations. For parameterisation $B$ and $C$, it was seen that the vast

262 majority of the LA-MRSA shedding pigs carried loads falling into the load classes L2-L4, which corresponded

263 to loads within the range of 10-9,999 CFU/nasal swab. In the median scenario, simulated load levels falling

264 within the lowest load class (L1) were only observed in the gestation, weaner and finisher unit, when

265 parameterisation B or C were applied (fig. 2E-F, K-L, \& N-O). Observations of loads above $>10,000$

266 CFU/swab were very rare in the median scenario, when using parameterisation B and C, and mainly

267 occurred in the farrowing unit (fig. $2 \mathrm{H}-\mathrm{I}$; barely visible on the figure due to the very low number of

268 observations). Amounts $>100,000 \mathrm{CFU} / \mathrm{swab}$ (L6) were only observed, when using parameterisation A. An

269 overview of the variance in the load distributions is provided in Appendix D, where percentiles for the

270 iterations are listed for each of the three parameterisations. 
A. Mat. unit - Par.A

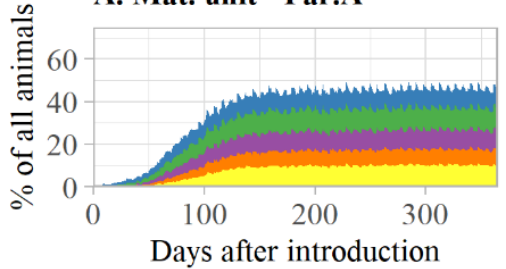

D. Gest. unit - Par.A

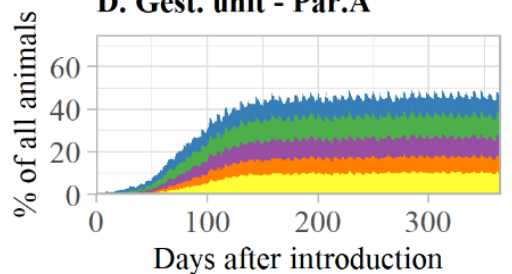

G. Farr. unit - Par.A

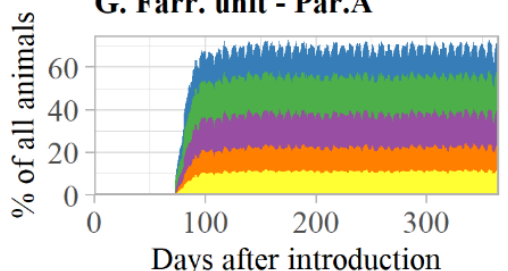

J. Wean. unit - Par.A

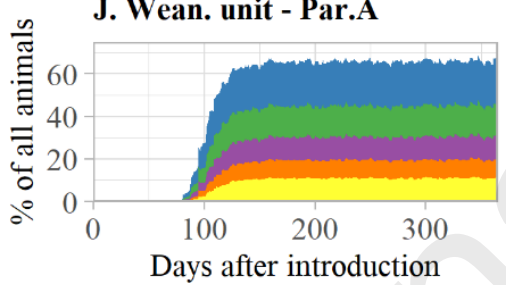

M. Fin. unit - Par. A

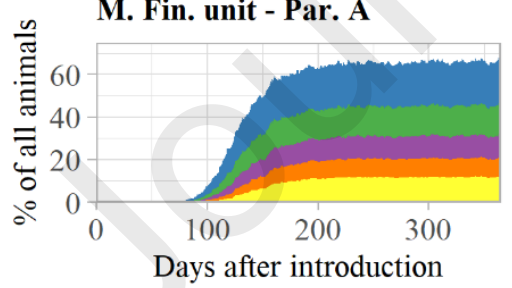

B. Mat. unit - Par.B

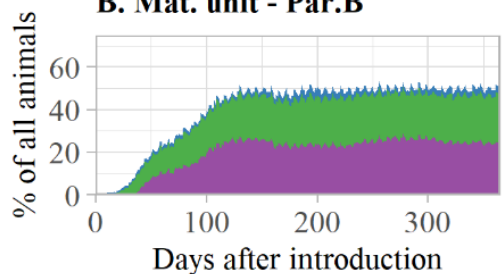

E. Gest. unit - Par.B

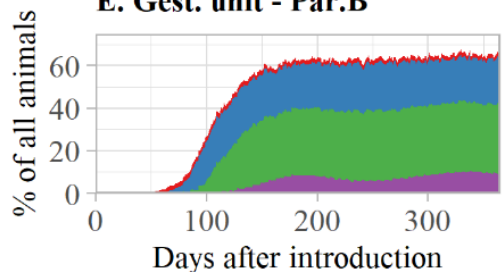

Days after introduction

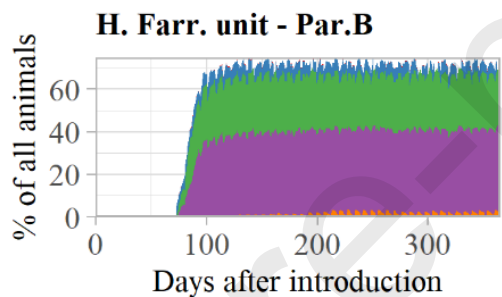

K. Wean. unit - Par.B

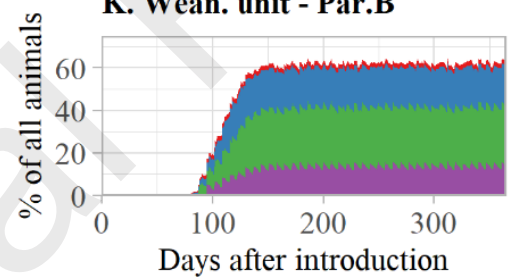

N. Fin. unit - Par.B

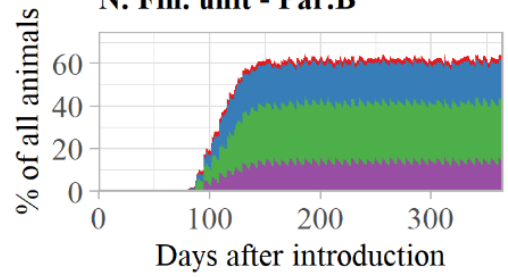

C. Mat. unit - Par.C

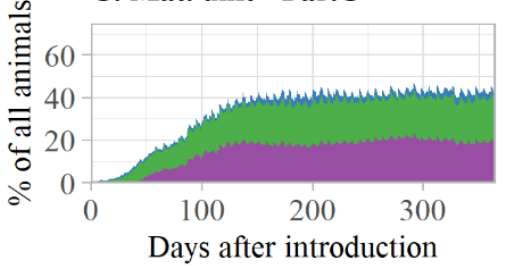

F. Gest. unit - Par.C

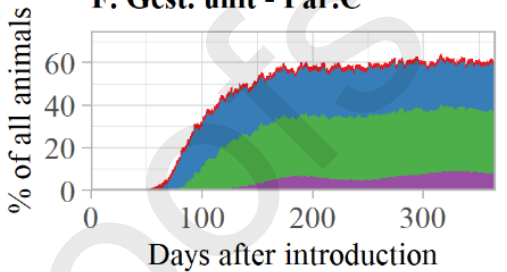

I. Farr. unit - Par.C

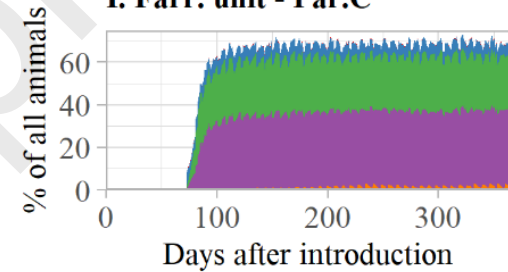

L. Wean. unit - Par.C

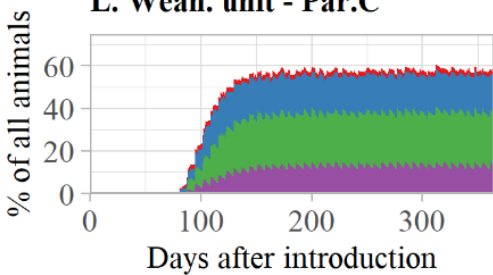

O. Fin. unit - Par.C

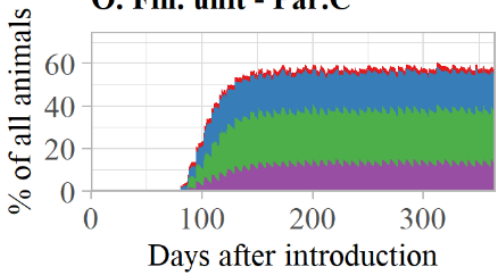

Fig. 2. Comparison of the distribution of load classes in the different barn units in the median scenario, when using parameterisation A, B and C respectively. L1 = 5-9 CFU, L2=10-99 CFU, L3=100-999 CFU, L4=1,000-9,999 CFU, L5=10,000-99,999 CFU, L6=100,000-999,999 CFU. 

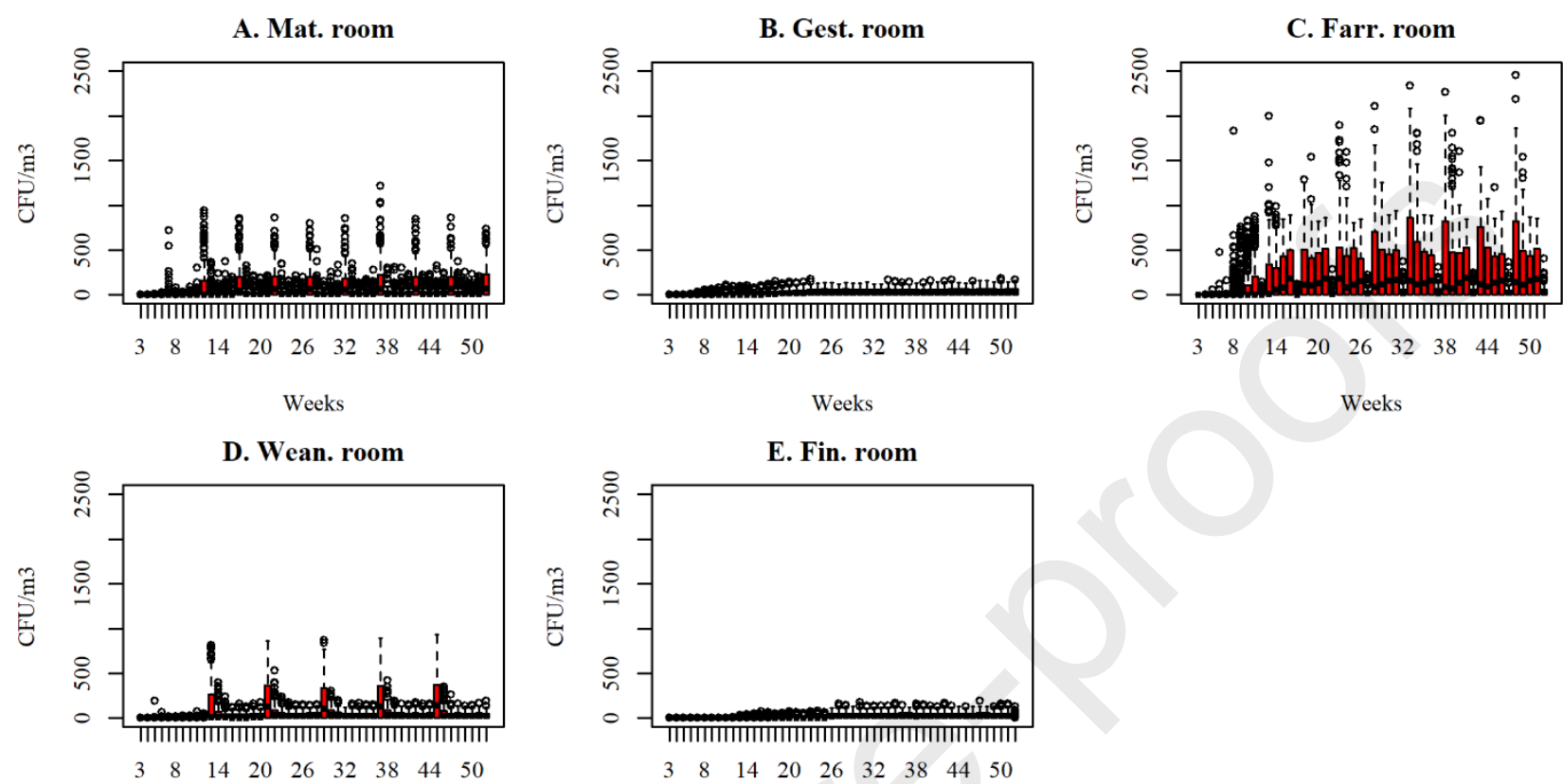

Fig. 3. Weekly boxplots for the simulated air levels in rooms in different barn unit in the basic scenario without any interventions Parameterization $B$. Panels: $A=$ first room in the mating unit, $B=$ first room in the gestation unit, $C=$ first room in the farrowing unit, $D=$ first room in the weaning unit, $E=$ first room in the finisher unit.

Within each type of unit similar patterns were observed within all rooms, except for the mating unit room

\subsection{Sensitivity analysis}


293 The results of sensitivity analysis indicated, that for all three parameterisation, the assumptions regarding 294 duration of shedding had a moderate influence. Using data from a different study, and thereby increasing 295 the duration, resulted in higher prevalence of LA-MRSA shedders in all barn units (Fig. 4B, E, H) and less 296 iterations, where LA-MRSA did not get established within the barn units (Fig. 5B, E, H). The assumptions 297 about the existence of persistent shedders seem to have a considerable influence, especially when using 298 parameterisation B and C, since when persistent shedding was not included in the model, the prevalence of 299 MRSA shedders was markedly lower, except in the farrowing unit, where only a limited decrease is 300 observed (fig. 4C, F, I). Furthermore, including no persistent shedders in the model resulted in more 301 iterations, where LA-MRSA did not spread within the herd (fig. 5C, F, I) 
A. Par. A

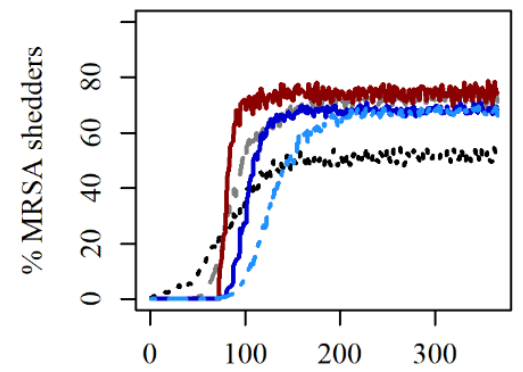

Days after first MRSA introduction

D. Par. B

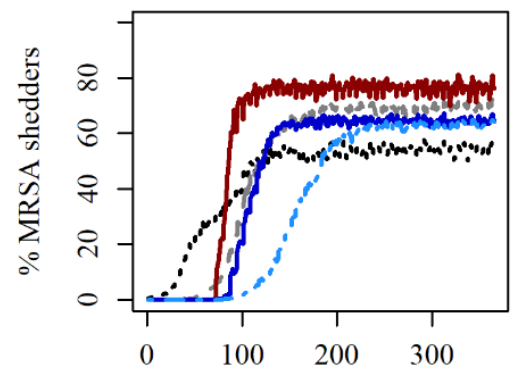

Days after first MRSA introduction

G. Par. C

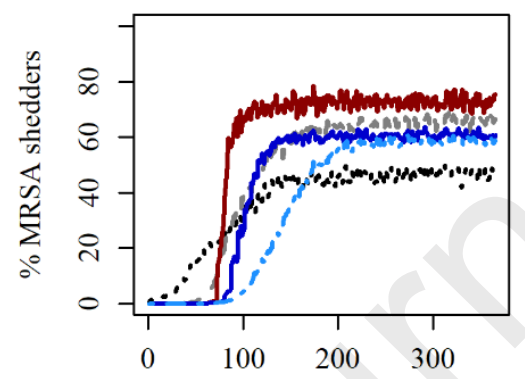

Days after first MRSA introduction
B. Par. A - alt. dur

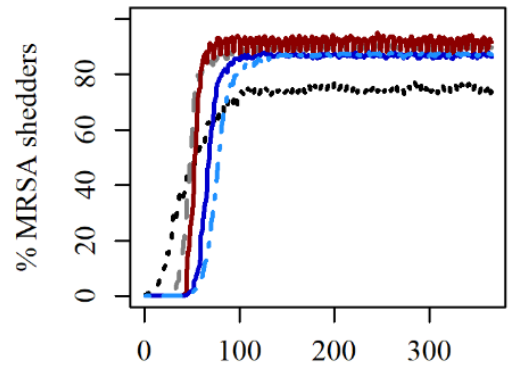

Days after first MRSA introduction

E. Par. B - alt. dur

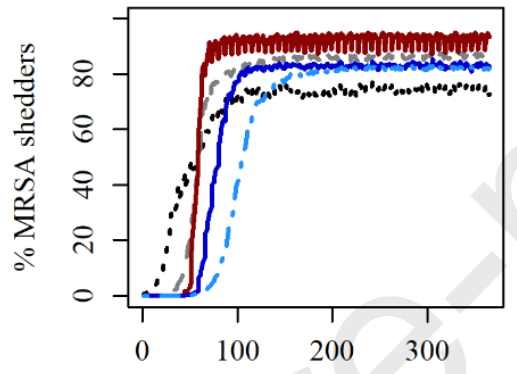

Days after first MRSA introduction

H. Par. C - alt. dur

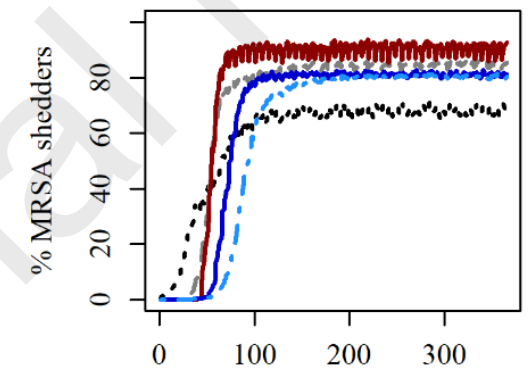

Days after first MRSA introduction
C. Par. A - no pers.

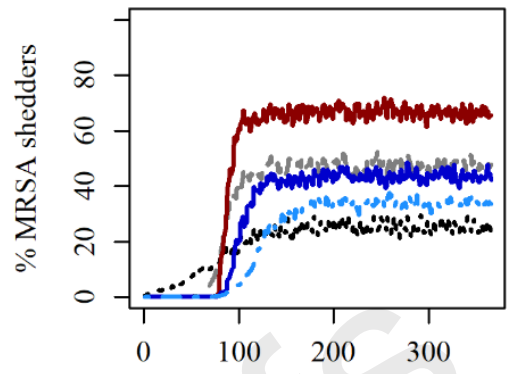

Days after first MRSA introduction

F. Par. B - no pers.

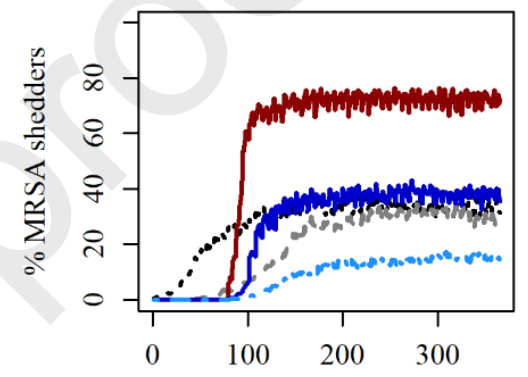

Days after first MRSA introduction

I. Par. C - no pers.

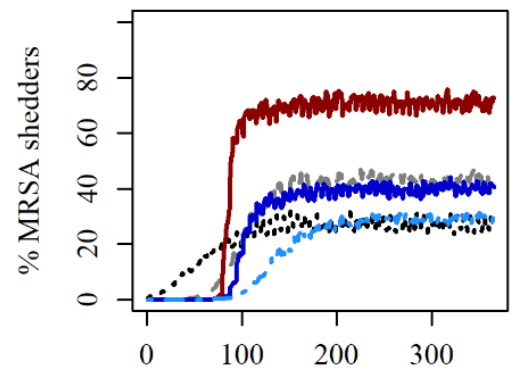

Days after first MRSA introduction

Fig 4. Results of sensitivity analysis. Alt. dur = alternative distribution for duration of carriage used. No pers. = It was assumed that there was no persistent shedders and all pigs only became transient carriers. 
A. Par. A

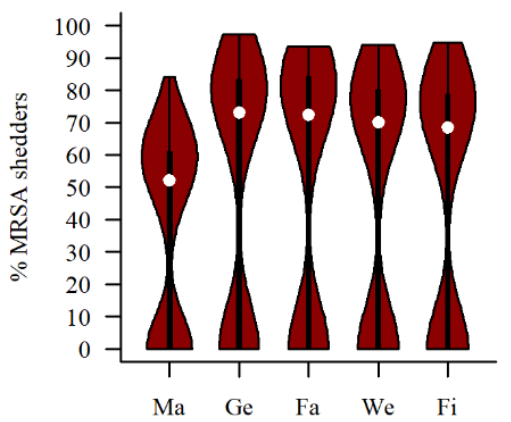

Stable unit

D. Par. B

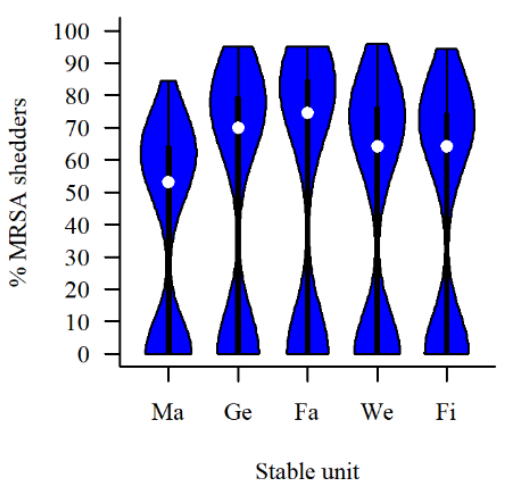

G. Par. C

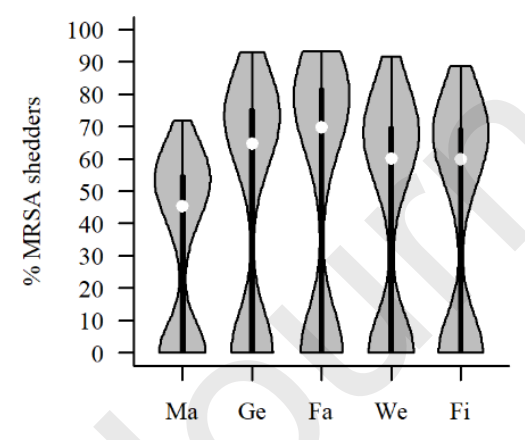

Stable unit
B. Par. A - alt. dur

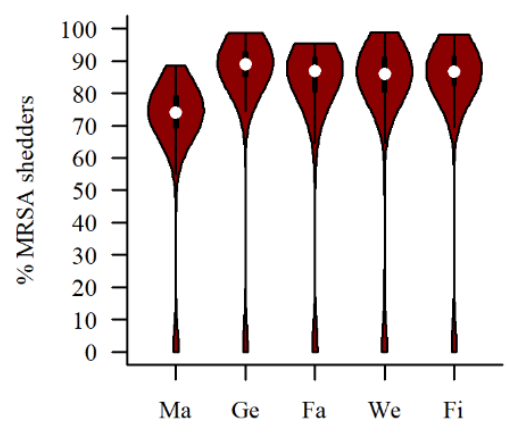

Stable unit

E. Par. B - alt. dur

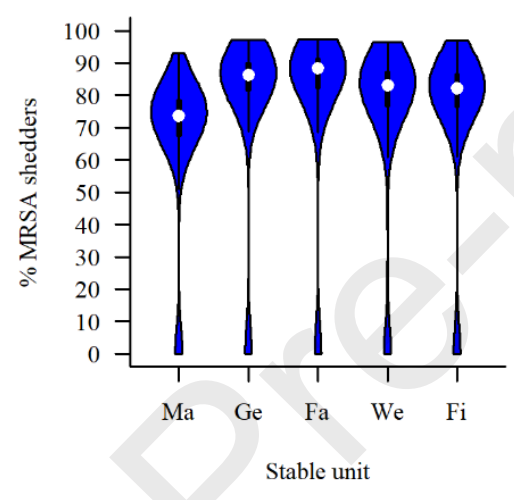

H. Par. C - alt. dur

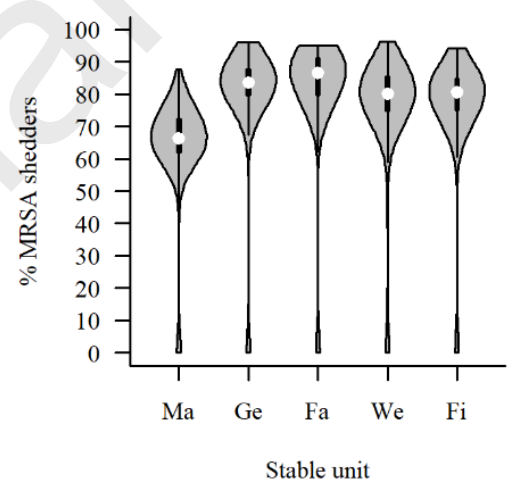

C. Par. A - no pers.

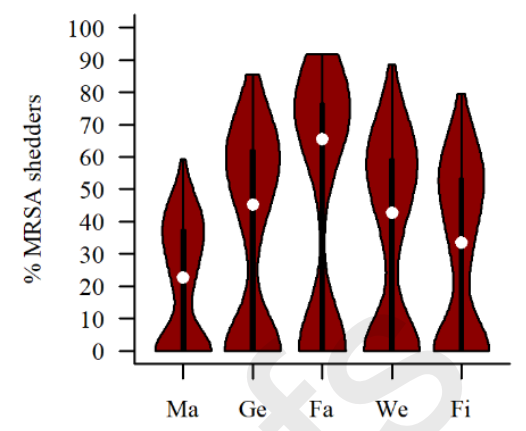

Stable unit

F. Par. B - no pers.

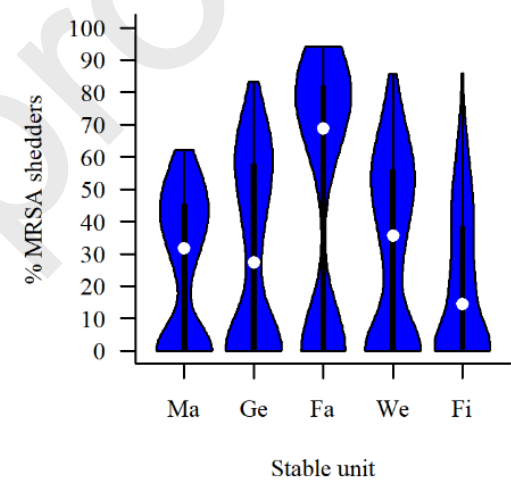

I. Par. C - no pers.

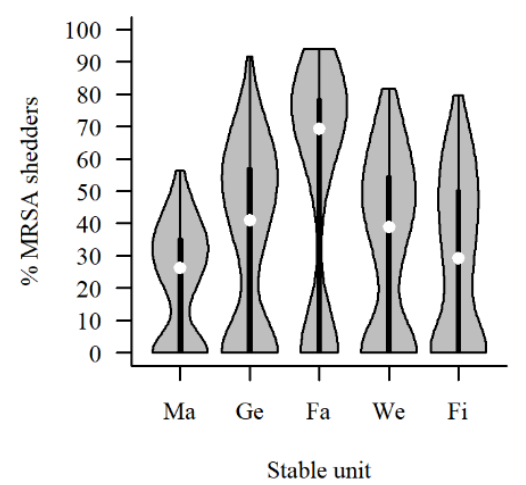

Fig. 5. Violinplots illustrating the distribution of the prevalence obtained in the sensitivity analysis scenarios using 250 iterations one year after introduction of LA-MRSA in the herd. Alt. dur = Alternative distribution for duration of shedding. No pers = no persistent shedders in these scenarios, all pigs were just assume to become intermittent shedders if 'infected'. Ma = Mating unit, $\mathrm{Ge}=$ Gestation unit, $\mathrm{Fa}=$ Farrowing unit, We $=$ Weaner unit, Fi $=$ Finisher unit.

\subsection{Validation}


In general, any unexpected output was followed-up upon in order to identify the cause. In order to validate the simulated load distribution among the pigs, simulation outputs was compared to the load distributions found in a study, where the load of LA-MRSA was determined semi-quantitatively in pigs on twenty farms (S4 fig, Espinosa-Gongora et al., 2015). For parameterisation B and C, the model predictions and real-life data for load carried by the pigs in the study conducted by Espinosa-Gongora et al., 2015, generally fell within the same range, since the majority of pigs were carrying load in the intervals $100-10,000 \mathrm{CFU} / \mathrm{swab}$ (Appendix D and S4 fig). Occurrence of pigs carrying high loads (>10,000 CFU/swab) occurred to varying degrees in the real-life observations on the 20 farms tested by Espinosa-Gongora et al., 2015 (0-20\% of the positive pigs on the farms, expect on one farm, where prevalence was low and one sample still had $>10,000$ CFU/swab). In the simulations, loads exceeding 10,000 CFU/swab were a rare event, when using parameterisation B (0-5.7\% of the positive pigs one year after introduction, median: $2.0 \%)$ and parameterisation C (0-3.8\% of positive pigs one year after introduction, median: $1.9 \%)$, whereas this was more common when using parameterisation $\mathrm{A}$ (14.0-22.9\% of the positive pigs one year after introduction, median: $18.1 \%)$. This means, that all the predicted proportions of pigs shedding high levels of LA-MRSA are within the range observed on real-life farms, albeit the proportions predicted when using parameterisation $B$ and $C$ are in the lower end of the scale.

An overview of the occurrence of the load levels in different barn units and the variance between iterations are given in Appendix D.

Among the predicted levels of LA-MRSA in the air, values up to approximately $12,500 \mathrm{CFU} / \mathrm{m}^{3}$ was observed in the simulations, with the majority of predictions falling within the interval $0-10^{3} \mathrm{CFU} / \mathrm{m}^{3}$. In observational studies on farms, levels in the range of $21-517 \mathrm{CFU} / \mathrm{m}^{3}$ (Angen et al., 2019) and 2-8,656 CFU $/ \mathrm{m}^{3}$ (Hansen, 2018) have been reported, however it must be expected that air levels can be influenced by age of the pigs, measurement methods, as well as a multitude of local factors, such as farm design, ventilation system and amount of dust in the stable. 


\subsubsection{Interventions directly leading to reduced transmission}

338 When reducing all the transmission rates to $70 \%, 40 \%$ and $10 \%$ of the original level, we saw that albeit this 339 led to reductions in the simulated median prevalences within the different barn units, in the median scenario LA-MRSA would not be eradicated from the herd (fig. 6). Reducing transmission to $40 \%$ of the initial level corresponded to the transmission observed, when there was no use of risk antimicrobials (betalactams and tetracyclines) in a previous transmission experiment (Broens et al., 2012a), and thus obtaining

343 this level should not be completely unrealistic. The prevalence outputs for the three different parameterisations seem to be very similar, meaning that the simulated prevalence results of this type of interventions are not very sensitive to the weighting of the different load classes (fig. 6). 
A. $70 \%$ - par. A

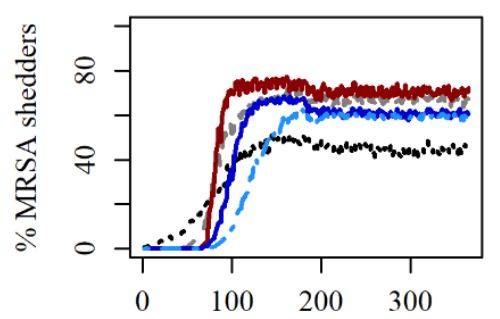

Days after first MRSA introduction

D. $40 \%$ - par. A

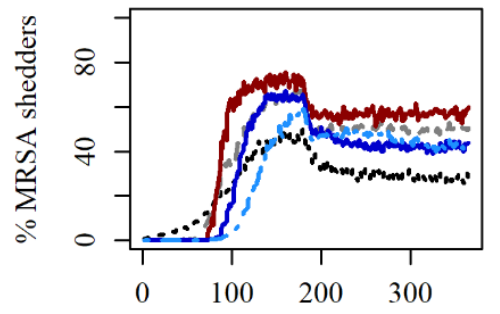

Days after first MRSA introduction

G. $10 \%$ - par. A

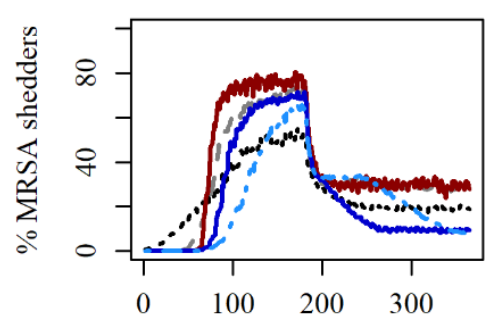

Days after first MRSA introduction
B. $70 \%$ - par. B

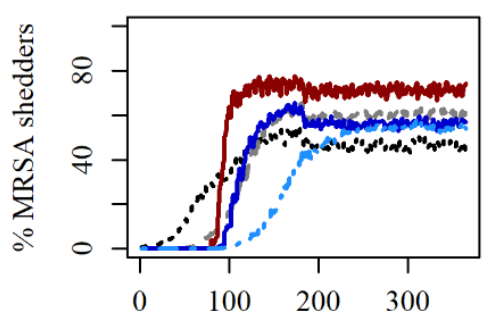

Days after first MRSA introduction

E. $40 \%$ - par. B

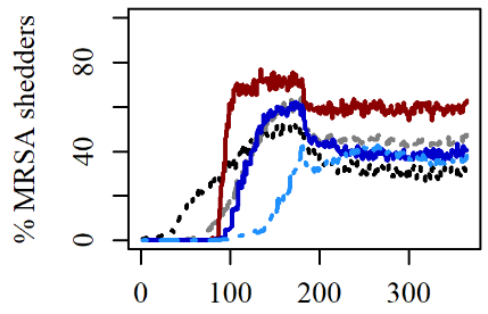

Days after first MRSA introduction

H. $10 \%$ - par. B

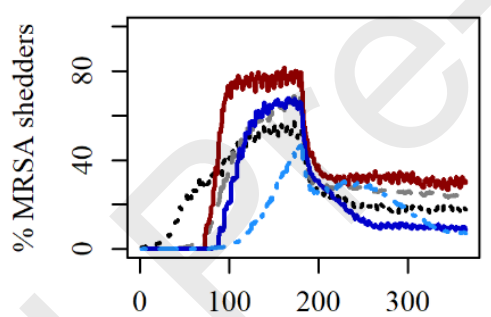

Days after first MRSA introduction
C. $70 \%$ - par. C

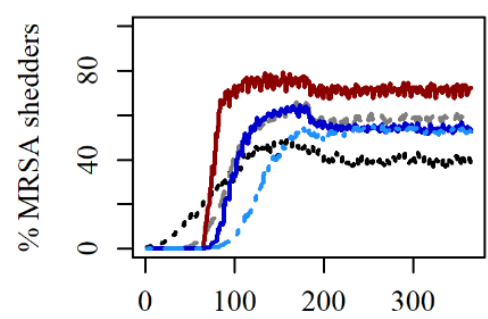

Days after first MRSA introduction

F. $40 \%$ - par. C

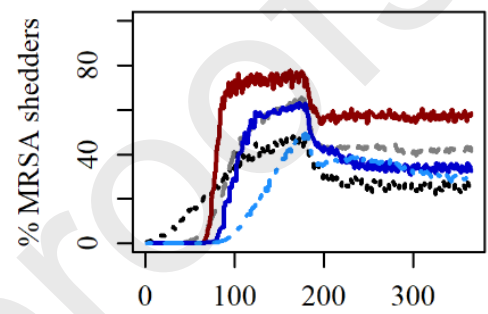

Days after first MRSA introduction I. $10 \%$ - par. C

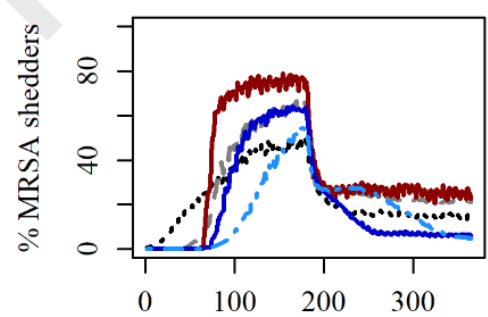

Days after first MRSA introduction

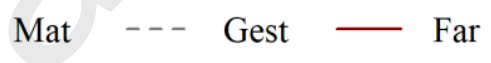

Wean .... Fini

Fig. 6.Development in the median prevalence of LA-MRSA shedders in the 5 different barn units over time, following a reduction in the transmission rates 180 days after introduction of LA-MRSA to $70 \%$ (panel A-C), $40 \%$ (panel D-F) or $10 \%$ (panel G-I) of the original level. Outputs are shown for when all three different parameterisation of the model (Parameterisation $A-$ panel $A, D$ and $G$, Parameterisation B - panel B, E and H, and Parameterisation C - panel C, F and I).

When taking into account the variation between iterations and looking at the development in the total prevalence of LA-MRSA shedders on the farm (fig. 7), it was seen that for some of the iterations the results of the different proportions of reduction were overlapping. 

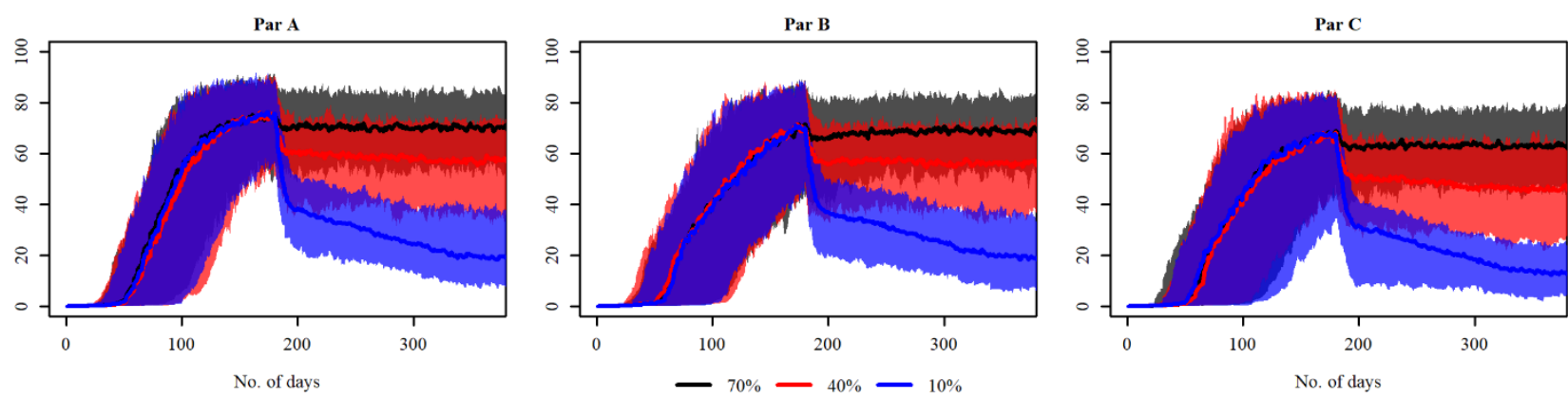

Fig. 7. Development in the median prevalence of LA-MRSA shedders over time, following a reduction in the transmission rates 180 days after introduction of LA-MRSA to $70 \%, 40 \%$ or $10 \%$ of the original level. The bands around each line indicates the interval between the $2.5 \%$ and $97.5 \%$ percentiles. Outputs are presented in a separate panel for each parameterisation (Par. A, Par. B and Par. C)

Examples of the effect of reduced transmission on the LA-MRSA air levels people entering the pig barns are exposed to are shown in fig. 8 for a room in the farrowing unit, i.e. a room with high concentration and high turnover of pigs and in S5 fig for a room in the gestation unit, i.e. a room with low concentration and low turnover of pigs. In both cases, the effect on air concentrations seem to differ considerably between parameterisation $A$ and the two other parameterisations, as a result of the much higher LA-MRSA loads obtained when using parameterisation A (fig. 8). 
A. $70 \%$ - par. A

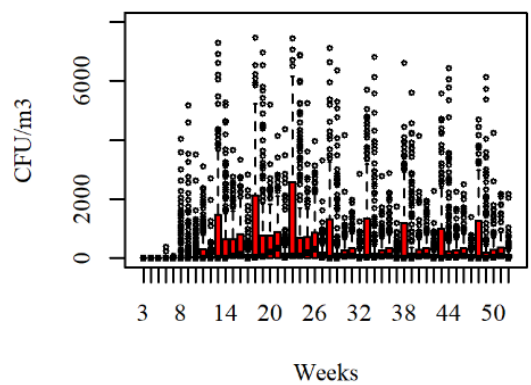

D. $40 \%$ - par. $A$

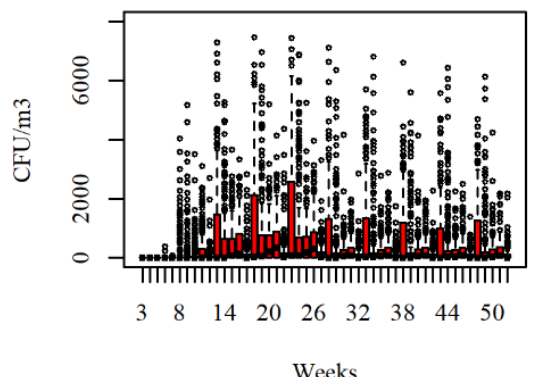

F. $10 \%$ - par. A

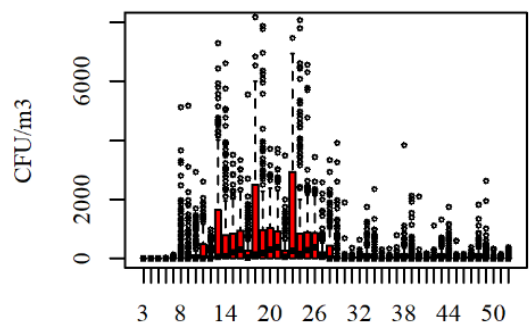

Weeks
B. $70 \%$ - par. B

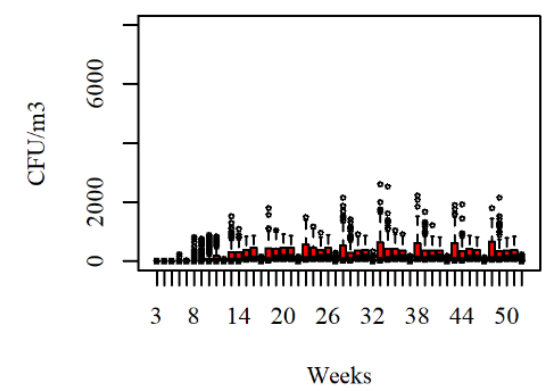

E. $40 \%$ - par. B

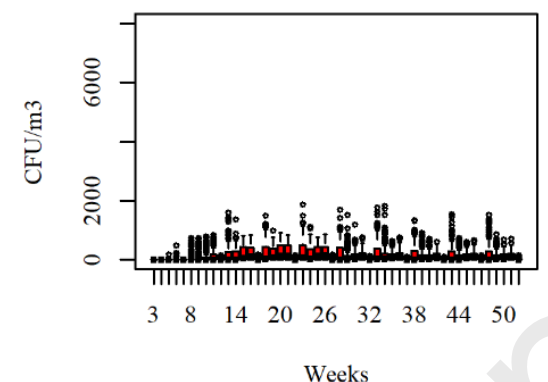

G. $10 \%$ - par. B

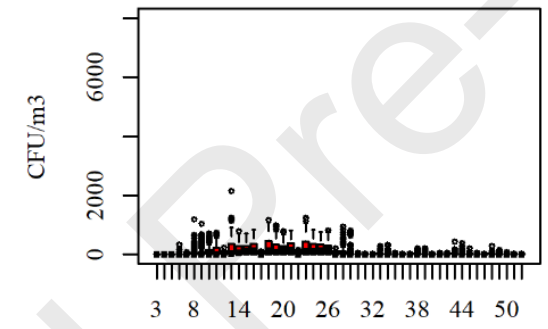

Weeks
C. $70 \%$ - par. C

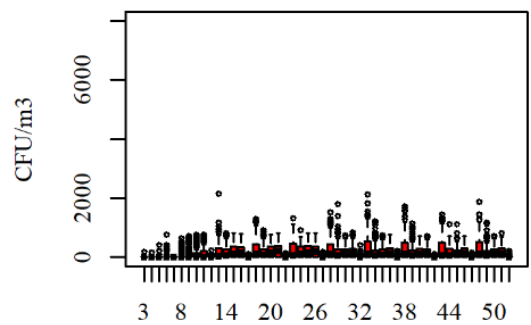

Weeks

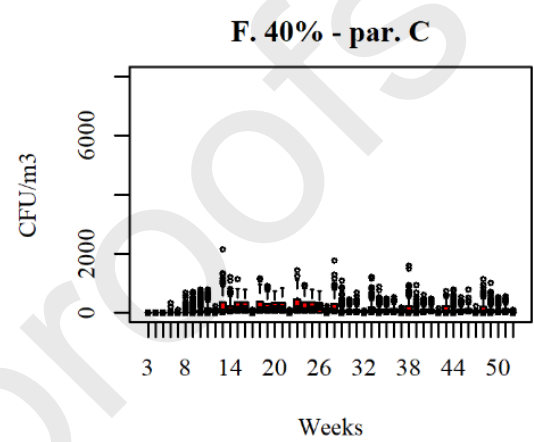

H. $10 \%$ - par. C

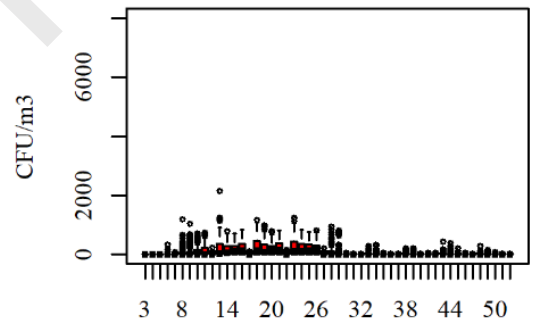

Weeks

Fig. 8. Simulated air levels of LA-MRSA within room no. 1 in the farrowing unit, following a reduction in the transmission rates 180 days after introduction of LA-MRSA to 70\% (panel A-C), 40\% (panel D-F) or 10\% (panel G-I) of the original level. Outputs are shown for when all three different parameterisation of the model (Parameterisation A - panel A, D and G, Parameterisation B - panel B, E and $\mathrm{H}$, and Parameterisation $\mathrm{C}-$ panel $\mathrm{C}, \mathrm{F}$ and $\mathrm{I})$. 
375 shown).

A. -2loadclasses - par. A

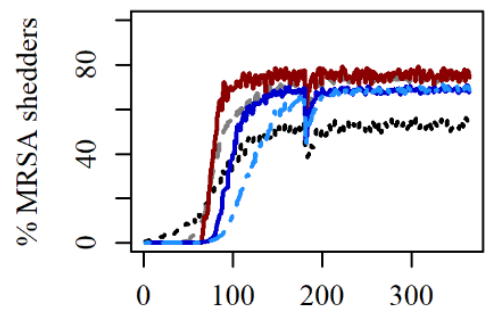

Days after first MRSA introduction
B. -2loadclasses - par. B

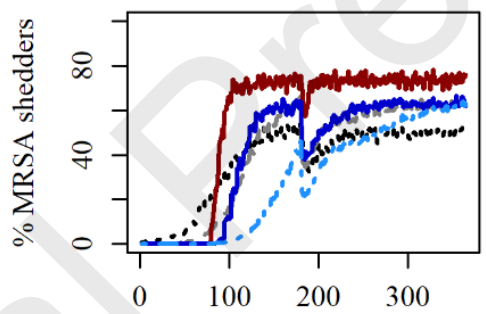

Days after first MRSA introduction
C. -2loadclasses - par. C

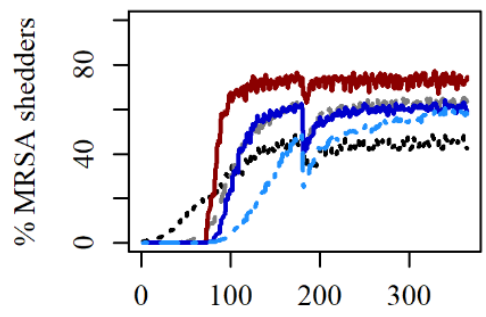

Days after first MRSA introduction

Fig. 9. Effect on the prevalence of LA-MRSA shedding animals of reducing the load in all pigs by two load classes at a single occasion using parameterisation A, B and C. Mat = mating unit, gest = gestation unit, far = farrowing unit, wean = weaning unit, fini $=$ finisher unit.

When looking at the effect of the same single point intervention on air levels (fig. 10), the observed day interventions. 
A. -2loadcl.- par. A

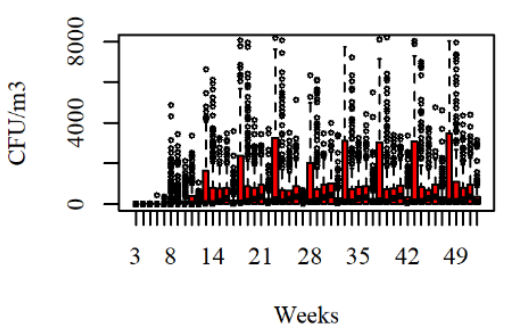

B. -2loadcl.- par. B

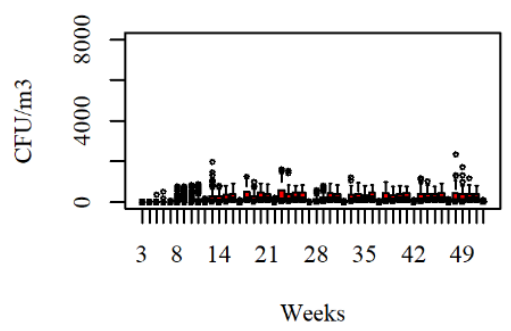

C. -2loadcl.- par. C

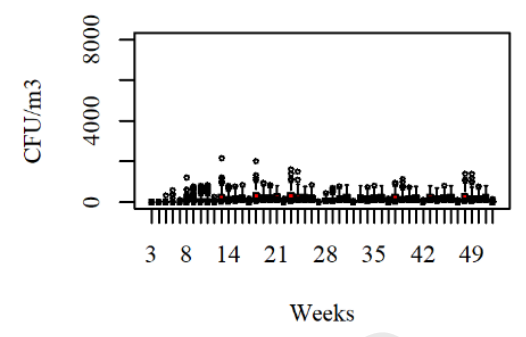

393

Fig. 10. The development in air levels following a single 2-load class reduction in pig load in week 26 using parameterisation A, B and $\mathrm{C}$ (example results, shown for a room in the farrowing unit).

\subsubsection{Continuous interventions}

It was seen that when interventions only were applied in a smaller fraction of the animals, the decline in prevalence in the units with fastest spread (the farrowing and weaner units) would be slower than in the other units (fig. 11A-C). When the intervention was applied to a larger fraction of the pigs, there would be a decline in all units almost immediately (fig. 11D-F).

A. $10 \%-1$ load class

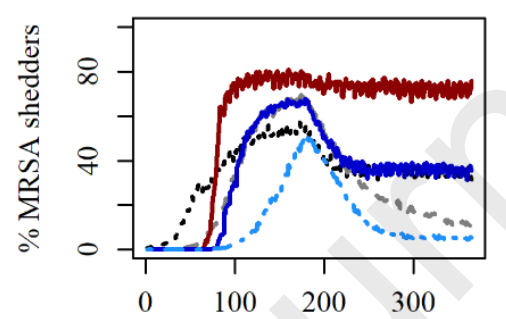

Days after first MRSA introduction

D. $40 \%-110 a d$ class

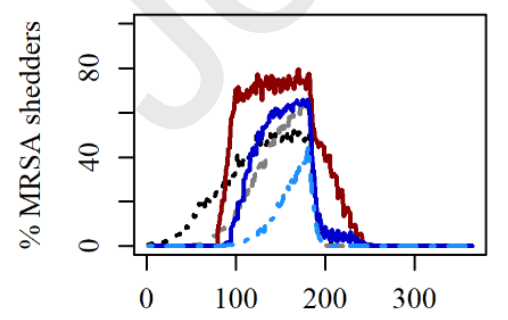

402
B. $20 \%-110 a d$ class

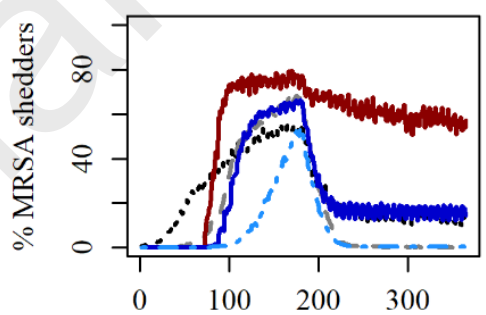

Days after first MRSA introduction

E. $50 \%$-1load class

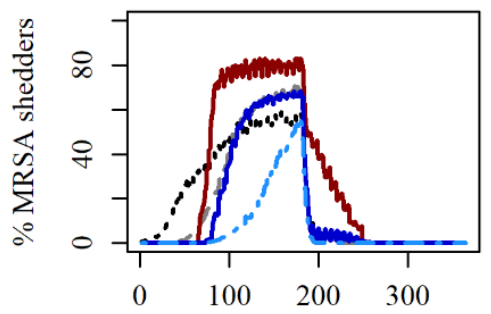

Days after first MRSA introduction
C. $30 \%-1$ load class

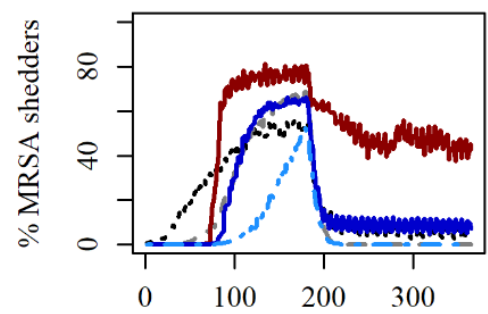

Days after first MRSA introduction F. $70 \%$-1load class

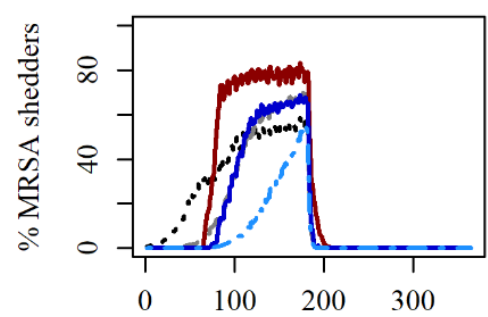

Days after first MRSA introduction 
Fig. 11. The effect on the prevalence within the five different barn units of conducting a load reduction of one load class in a certain fraction of randomly selected animals every day. This has been exemplified by the use of parameterisation B. Mat $=$ mating unit, Gest = gestation unit, Farr = farrowing unit, Wean = weaning unit, Fini = finisher unit

When comparing the median overall prevalence of LA-MRSA shedding pigs on the farm following daily reductions in various fractions of the pigs $(2.5 \%-60 \%)$, it was observed that a reduction in approximately $50 \%$ of the pigs, was needed in order to get the median prevalence to decline to zero (fig. 12A). However, when taking into account the variation between iterations, it became clear that in some cases, the predicted prevalence would also decline to zero, when the reduction was only applied to $30 \%$ of the pigs (fig. 12B, red band).
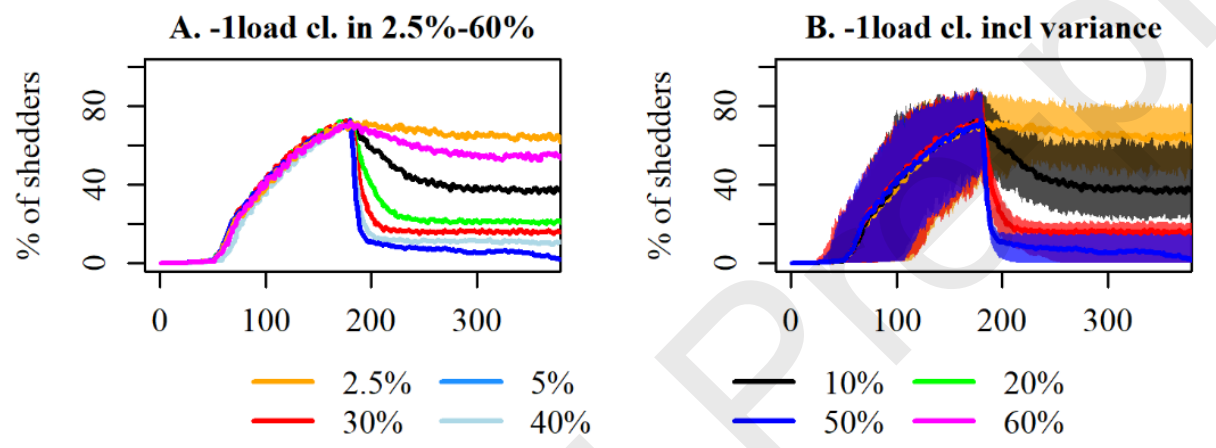

Fig. 12. The effect on the overall prevalence of LA-MRSA shedding pigs on the farm following a load reduction of one load class in a certain fraction of randomly selected animals every day. Panel A illustrates the median development following daily reductions in $2.5 \%, 5 \%, 10 \%, 20 \%, 30,40 \%, 50 \%$ and $60 \%$ of the animals, whereas panel $\mathrm{B}$, shows the median prevalence for selected scenarios from panel A, including bands covering the $2.5 \%-97.5 \%$ percentiles for the variation. Parameterisation $B$ was used for all simulations presented on this figure.

However, when looking at the effect of the same reduction on the amount of LA-MRSA in the air within the farrowing unit (fig. 13), a considerable decline was also seen, even when the load reduction was only applied to $10 \%$ of the pigs every day (fig. 13A). 
A. -1loadcl.- 10\%

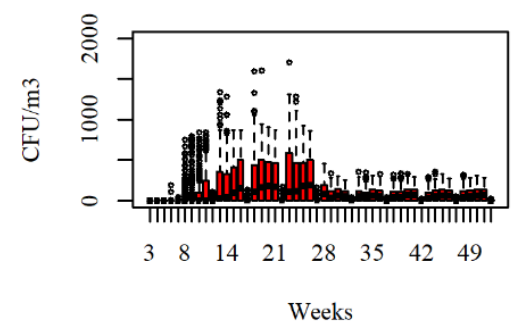

D. -1loadcl.- $40 \%$

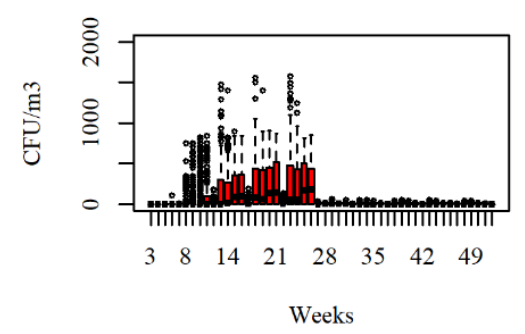

B. -1loadcl.- $20 \%$

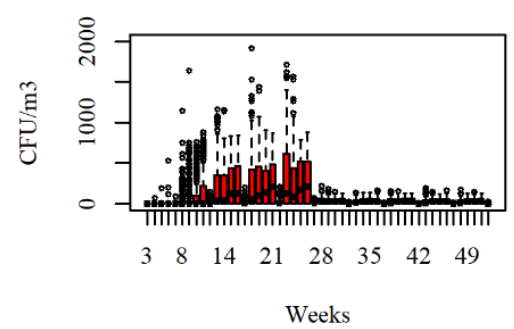

E. -1loadcl.- $\mathbf{5 0 \%}$

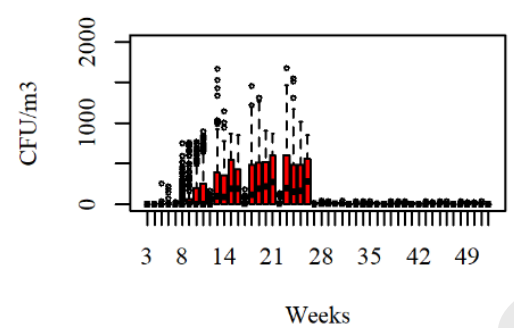

C. -1loadcl.- $30 \%$

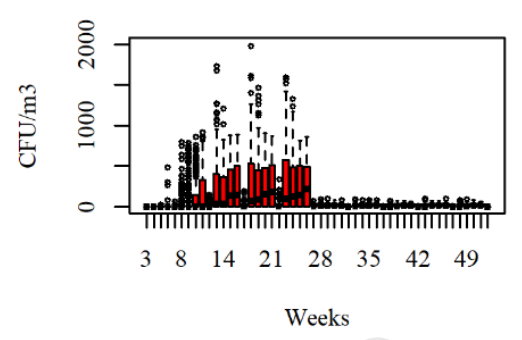

F. -1loadcl.- $70 \%$

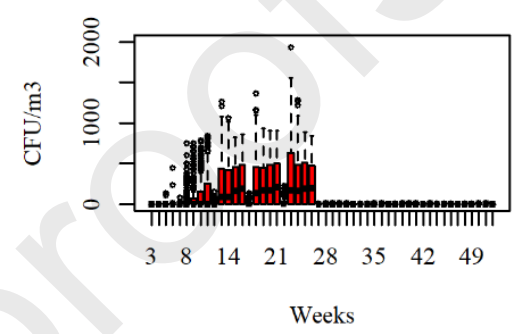

Fig. 13. The effect on air levels in room number one in the farrowing unit of conducting a load reduction of one load class in a certain fraction of randomly selected animals every day. This has been exemplified by the use of parameterisation B.

The predicted effect on the load carried by the animals across barn units, when the load was reduced by one load class in $20 \%$ of the pigs every day was very much as one would expect (fig. 14). However, there was a very clear difference between the different types of barn units; the higher initial level, the slower decline (fig. 14C). A similar development was observed in air (results not shown). 
A. -20\% 1loadred - Mat.

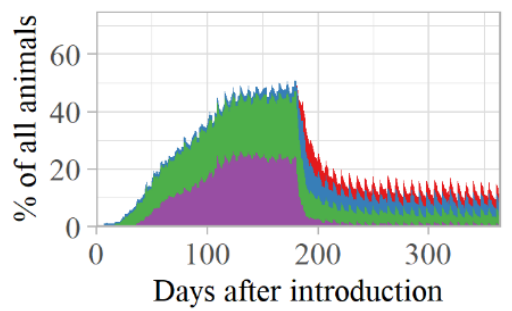

D. -20\% 1loadred - Wean.

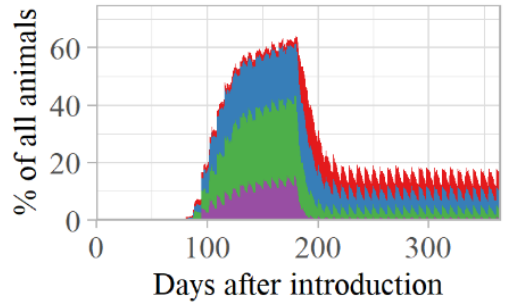

B. $-\mathbf{2 0} \% 1$ loadred - Gest.

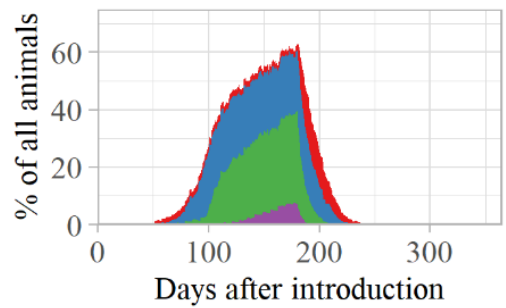

E. -20\% 1loadred - Fin.

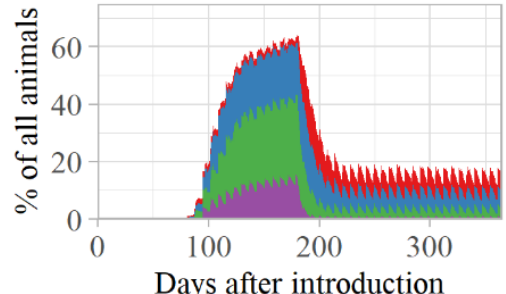

C. $-\mathbf{2 0} \%$ 1loadred - Farr.

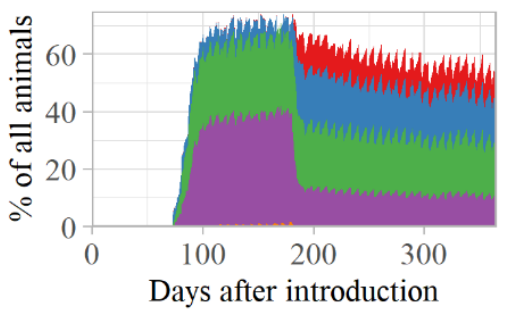

Load
434

Fig. 14. The effect on load levels carried by the pigs across different types of barn unit, when conducting a load reduction of one load class in $20 \%$ of randomly selected animals every day. This has been exemplified by the use of parameterisation $B$.

When introducing a reduction of the load carried by all pigs in a given type of barn unit of the size of one load class, it was observed that for most barn units, the reduction also had an impact in the next barn unit, the pigs would be moved into according to the production cycle (fig. 15). This means, that a reduction in the mating unit (fig. 15A), also had an impact in the gestation unit, and a reduction in the farrowing unit (fig. 15C) also had an impact in the weaner and finisher unit, as well as a reduction in the weaner unit also led to reduced occurrence in the finisher unit (fig. 15D). Reductions in the gestation unit, where the sows remain for a relatively long time (fig. 15B), did not have any clear effect on the prevalence of LA-MRSA shedders in the other units. 
A. Mat. -1load class

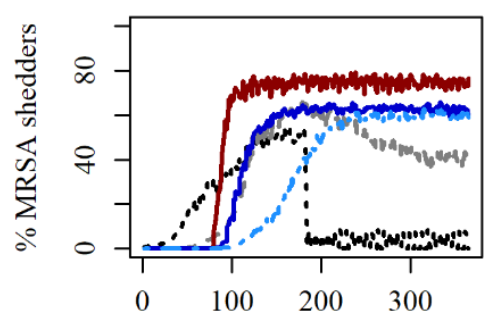

Days after first MRSA introduction

D. Wean. -1load class

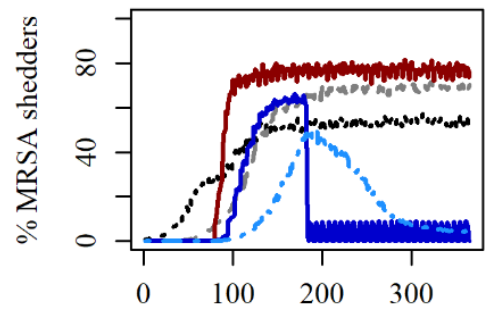

Days after first MRSA introduction
B. Gest. -1load class

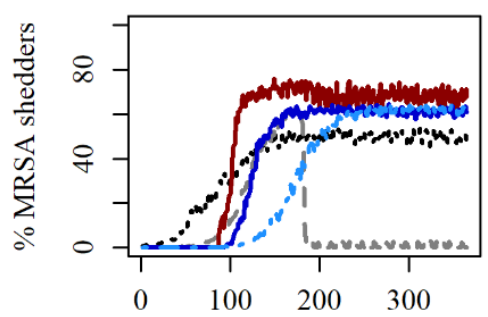

Days after first MRSA introduction

E. Fin. -1load class

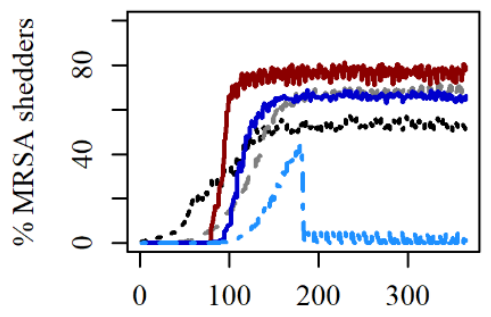

Days after first MRSA introduction
C. Farr. -1load class

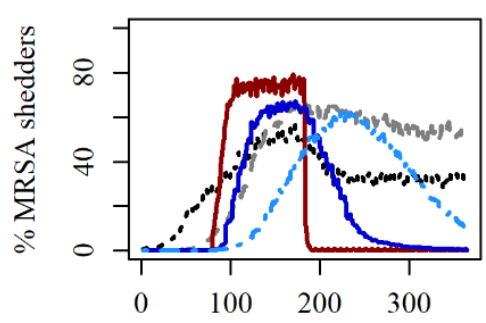

Days after first MRSA introduction
446

447

448

449

450

451

452

453

454

455

456

457

458

459

460

461

462

\section{Discussion}

Not many models for spread of LA-MRSA exist, neither for spread between pigs nor for spread to humans.

To our best knowledge, currently only one simulation model for LA-MRSA attempting at bridging the gap between pigs and humans has been published (Porphyre et al., 2012). This model is a meta-population model, which focuses on spread of LA-MRSA between different population groups, and therefore have a completely different focus than the present model. Thus, it does not include spread within farm and thereby the possibility of assessing the effect of within-farm interventions on human exposure to LA-MRSA for those entering the pig barns. 
Building this model has aided in highlighting some of the most important knowledge gaps regarding transmission of LA-MRSA. The association between the nasal load carried by an individual pig, and its ability to pass on LA-MRSA to other pigs has not been determined. However, intuitively one would assume that the more LA-MRSA a pig carries, the more it will shed to barn air, surroundings and during contact to pen mates. There are some indications of an association between higher nasal load and shedder/carrier-type in both pigs and humans, since persistent carriers tend to carry higher MRSA loads (Espinosa-Gongora et al., 2015; Verhoeven et al., 2012). Not much is known about the kinetics, growth and survival of LA-MRSA in the nasal cavity of the pigs, or any other possible environmental niches in the barn environment, since most longitudinal studies of the occurrence of LA-MRSA in pigs, only report aggregated qualitative data on group level rather than quantitative data on the individual level.

The use of load classes causes an artificial subdivision of something that by nature is continuous, but for simplicity and due to the uncertainty related to the actual influence of load, this approach was selected. A similar approach has been used in other disease spread models that both takes different types of shedders and different quantities of bacteria shed by each animals into account, e.g. the Q-fever model by Courcoul et al., 2011.

In terms of simulating interventions, one major limitation of the model is that it was not possible to model the impact of reductions in air concentrations on the load carried by the pigs, since it is unknown if such reductions will actually cause a decline in the load carried by the pigs. Additionally, the kinetics and magnitude of such decline are also unknown.

The three different parameterisations generally gave relatively similar predictions of the development in the prevalence of LA-MRSA shedders. However, for the load levels in pigs and concentrations of LA-MRSA in the barn air, parameterisation $B$ and $C$ gave similar predictions, which were lower than the predictions obtained when using parameterisation A. It can be discussed, whether the high amount of pigs carrying loads exceeding $>10,000 \mathrm{CFU} / \mathrm{swab}$, when using parameterisation method $\mathrm{A}$ is realistic, given that in the 
available observational data, these animals only constituted a limited fraction of the MRSA shedders

(Espinosa-Gongora et al., 2015). However, these animals might be of high biological importance, which could be an argument for preferring parameterisation B or C.

There was considerable variation in the predicted air concentrations of LA-MRSA depending on the unit in question and the selected parameterisation. Meaningful comparison with reported air levels in other studies are hampered by the fact that only few studies are available and that different methods have been used, such as use of electrostatic dust collectors (EDC) or direct air sampling using either impingement or impactor methods. For the last two methods, different sampling times and/or air flow might apply. Additionally, air levels are naturally expected to vary depending on level of contamination, as well as on farm type, age and number of pigs housed within the sampling unit. Furthermore, one could speculate that other local factors such as ventilation and type of bedding might also have an effect. In general reported air levels seem to fall within the range of $0-10^{4} \mathrm{CFU} / \mathrm{m}^{3}$ with the majority within the range of $0-500 \mathrm{CFU} / \mathrm{m}^{3}$ (Angen et al., 2019, 2017; Bos et al., 2016; Friese et al., 2012; Madsen et al., 2018), meaning that the levels predicted by the model might not be unrealistic. However, in the predictions of air concentrations within rooms, there was considerable variation between iterations and many outliers, especially for the sections in the farrowing unit, where the levels were highest. This also means that there will be considerable uncertainty regarding how much LA-MRSA humans are exposed to when entering the barn units. In reallife, this will also depend on what activity these persons (and the pigs) engage in. For example, activities causing movement of the pigs, dust or dirt layers on barn surfaces, such as feeding or in the extreme case, high pressure cleaning, might lead to increased concentrations of LA-MRSA in the air (Madsen et al., 2018). Naturally, direct contact to the pigs might also influence whether a person entering the pig barns becomes contaminated (Angen et al., 2017), as well as the exposure time. In addition, hygiene measures and hostrelated factors also might have an impact. In a study on a pig farm, the $50 \%$ contamination value (for a 1 hour stay) was estimated to $20-90$ airborne $\mathrm{CFU} / \mathrm{m}^{3}$ by bootstrapping (Angen et al., 2019). This only 
resulted in short-term contamination among the participants. In the present study, the predicted level in most rooms were within or above this range.

Although prediction of prevalence was similar in the different parameterisation methods, the effect of interventions could be different, which point out the need for longitudinal field studies to avail data to parameterize the model.

Regardless of the parameterisation used, reducing transmission (e.g. through changed antimicrobial consumption patterns) would reduce the load of the bacteria in the pigs.

According to the predictions, reducing the load in pigs would also reduce the load in air and thereby the risk for humans. It is quite interesting that reducing the load with one load class (i.e. one log unit, if greater than load class L2) in e.g. only $20 \%$ of the pigs every day, would reduce the prevalence and air concentrations quite substantially (fig. 8 and 9). Such a reduction in $30 \%$ of the pigs everyday would likely be able to eradicate LA-MRSA from the herd after a period of time, assuming a constant application of the measure that reduces the load. Although, it is unknown which measure that would actually be able to do this, it is an option to investigate strategies/technologies that can reduce the load of LA-MRSA in pigs to limit its spread to humans. It is important though to note that the predictions of the degree of reduction is dependent on the selected parameterisation, as well as the validity of the assumptions used in the model, which again points out the need for data to draw proper conclusions about the effectiveness of strategies to limit the spread of LA-MRSA to humans.

Our goal of building this model is not to provide exact values for risk reduction, but to avail a model that can be used for studying the effect of various types of interventions mechanistically, once more relevant data become available. In addition, we wanted to study whether reducing the load given different ways of parameterisation can reduce the air concentrations and hence risk of LA-MRSA spread to humans.

Collection of more data on the influence of load is crucial for getting a better understanding of which interventions that might still have some potential in countries, where LA-MRSA has already spread to the 
535 majority of the pig population. In these countries, the main goal might now be to prevent transmission into 536 any remaining clean farms, as well as to reduce the spread of LA-MRSA into the general human population, 537 rather than aiming for complete eradication of LA-MRSA, as this may be economically unfeasible (Olsen et 538 al., 2018).

539

\section{Acknowledgements}

541 This work was supported by the Ministry of Environment and Food of Denmark through The Danish Agrifish 542 Agency (J. no. 33010-NIFA-14-612). 
544

545

546

547

548

549

550

551

552

553

554

555

556

557

558

559

560

561

562

563

564

565

566

567

568

569

570

571

572

573

574

575

576

577

578

\section{References}

Angen, Ø., Feld, L., Larsen, J., Rostgaard, K., Skov, R., Madsen, A.M., Larsen, A.R., 2017. Transmission of Methicillin-Resistant Staphylococcus aureus to Human Volunteers Visiting a Swine Farm. Appl. Environ. Microbiol. 83, 1-10.

Angen, $\varnothing$. , Skade, L., Urth, T.R., Andersson, M., Bækbo, P., Larsen, A.R., 2019. Controlling Transmission of MRSA to Humans During Short-Term Visits to Swine Farms Using Dust Masks. Front. Microbiol. 9, 1-6. https://doi.org/10.3389/fmicb.2018.03361

Bækbo, P., Sommer, H.M., Espinosa-gongora, C., Pedersen, K., Toft, N., 2018. Ingen effekt af biocidet BioVir på forekomsten af MRSA i stalden (in Danish). Available as PDF from: https://svineproduktion.dk/publikationer/kilder/lu medd/2018/1144. Last accessed: 05-12-2019.

Bangerter, P.D., Sidler, X., Perreten, V., Overesch, G., 2016. Longitudinal study on the colonisation and transmission of methicillin-resistant Staphylococcus aureus in pig farms. Vet. Microbiol. 183, 125-134. https://doi.org/10.1016/j.vetmic.2015.12.007

Becker, K., Ballhausen, B., Kahl, B.C., Köck, R., 2015. The clinical impact of livestock-associated methicillinresistant Staphylococcus aureus of the clonal complex 398 for humans. Vet. Microbiol. https://doi.org/10.1016/j.vetmic.2015.11.013

Bos, M.E.H., Verstappen, K.M., van Cleef, B.A.G.L., Dohmen, W., Dorado-García, A., Graveland, H., Duim, B., Wagenaar, J. A, Kluytmans, J.A.J.W., Heederik, D.J.J., 2016. Transmission through air as a possible route of exposure for MRSA. J. Expo. Sci. Environ. Epidemiol. 26, 263-269.

https://doi.org/10.1038/jes.2014.85

Broens, E.M., Espinosa-Gongora, C., Graat, E.A.M., Vendrig, N., Van Der Wolf, P.J., Guardabassi, L., Butaye, P., Nielsen, J.P., De Jong, M.C.M., Van De Giessen, A.W., 2012a. Longitudinal study on transmission of MRSA CC398 within pig herds. BMC Vet. Res. 8, 58. https://doi.org/10.1186/1746-6148-8-58

Broens, E.M., Graat, E.A.M., van de Giessen, A.W., Broekhuizen-Stins, M.J., de Jong, M.C.M., 2012b. Quantification of transmission of livestock-associated methicillin resistant Staphylococcus aureus in pigs. Vet. Microbiol. 155, 381-388. https://doi.org/10.1016/j.vetmic.2011.09.010

Chuang, Y., Huang, Y., 2015. International Journal of Antimicrobial Agents Livestock-associated meticillinresistant Staphylococcus aureus in Asia: An emerging issue? Int. J. Antimicrob. Agents 45, 334-340. https://doi.org/10.1016/j.ijantimicag.2014.12.007

Courcoul, A., Hogerwerf, L., Klinkenberg, D., Nielen, M., Vergu, E., Beaudeau, F., 2011. Modelling effectiveness of herd level vaccination against $Q$ fever in dairy cattle. Vet. Res. 42, 68. https://doi.org/10.1186/1297-9716-42-68

Crombé, F., Argudín, M.A., Vanderhaeghen, W., Hermans, K., Haesebrouck, F., Butaye, P., 2013. Transmission Dynamics of Methicillin-Resistant Staphylococcus aureus in Pigs. Front. Microbiol. 4, 57. https://doi.org/10.3389/fmicb.2013.00057 
Cuny, C., Wieler, L., Witte, W., 2015. Livestock-Associated MRSA: The Impact on Humans. Antibiotics 4, 521-543. https://doi.org/10.3390/antibiotics4040521

Espinosa-Gongora, C., Dahl, J., Elvstrøm, A., van Wamel, W.J., Guardabassi, L., 2015. Individual predisposition to Staphylococcus aureus colonization in pigs on the basis of quantification, carriage dynamics, and serological profiles. Appl. Environ. Microbiol. 81, 1251-6. https://doi.org/10.1128/AEM.03392-14

Espinosa-Gongora, C., Panduro, P., Saxmose, S., 2013. Effect of a disinfectant powder on methicillinresistant Staphylococcus aureus in pigs, bedding and air samples under simulated farm conditions.

Feld, L., Bay, H., Angen, Ø., Larsen, A.R., Madsen, A.M., 2018. Survival of LA-MRSA in Dust from Swine Farms. Ann. Work Expo. Heal. 1-10. https://doi.org/10.1093/annweh/wxx108

Friese, A., Schulz, J., Hoehle, L., Fetsch, A., Tenhagen, B.-A., Hartung, J., Roesler, U., 2012. Occurrence of MRSA in air and housing environment of pig barns. Vet. Microbiol. 158, 129-135. https://doi.org/10.1016/j.vetmic.2012.01.019

Hansen, J.E., 2018. Methicillin-resistant Staphylococcus aureus in Danish production animals. Technical University of Denmark. https://backend.orbit.dtu.dk/ws/portalfiles/portal/149112156/PhD_thesis_Julie_Elvekj_r_Hansen.pdf

Harper, A.L., Ferguson, D.D., Larson, K.R.L., Hanson, B.M., Male, M.J., Donham, K.J., Smith, T.C., 2010. An overview of livestock-associated MRSA in agriculture. J. Agromedicine 15, 101-104. https://doi.org/10.1080/10599241003627110

Khanna, T., Friendship, R., Dewey, C., Weese, J.S., 2008. Methicillin resistant Staphylococcus aureus colonization in pigs and pig farmers. Vet. Microbiol. 128, 298-303. https://doi.org/10.1016/j.vetmic.2007.10.006

Madsen, A.M., Kurdi, I., Feld, L., Tendal, K., 2018. Airborne MRSA and Total Staphylococcus aureus as Associated With Particles of Different Sizes on Pig Farms. Ann. Work Expo. Heal. 1-12. https://doi.org/10.1093/annweh/wxy065

Olsen, J. V, Calvo-Artavia, F.F., Sandøe, P., Toft, N., 2018. Modeling the cost of eradicating livestockassociated methicillin-resistant Staphylococcus aureus in countries with a high proportion of positive herds. Prev. Vet. Med. 158, 97-105. https://doi.org/10.1016/j.prevetmed.2018.07.010

Porphyre, T., Giotis, E.S., Lloyd, D.H., Stärk, K.D.C., 2012. A Metapopulation Model to Assess the Capacity of Spread of Meticillin-Resistant Staphylococcus aureus ST398 in Humans. PLoS One 7. https://doi.org/10.1371/journal.pone.0047504

R Core team, 2015. R Core Team. R - A Language and Environment for Statistical Computing. R Foundation for Statistical Computing, Vienna, Austria. ISBN 3-900051-07-0, URL http//www.R-project.org/. 
612

613

Rosen, K., Roesler, U., Merle, R., Friese, A., 2018. Persistent and Transient Airborne MRSA Colonization of Piglets in a Newly Established Animal Model. Front. Microbiol. 9, 1-12. https://doi.org/10.3389/fmicb.2018.01542

Sahibzada, S., Abrah, S., Coombs, G.W., Pang, S., Jordan, D., Heller, J., 2017. Transmission of highly virulent community-associated MRSA ST93 and livestock-associated MRSA ST398 between humans and pigs in Australia. Sci. Rep. 1-11. https://doi.org/10.1038/s41598-017-04789-0

Schulz, J., Bao, E., Clauß, M., Hartung, J., 2013. The potential of a new air cleaner to reduce airborne microorganisms in pig house air: preliminary results. Berl. Munch. Tierarztl. Wochenschr. 4, 143-148. https://doi.org/10.2376/0005-9366-126-143

Schulz, J., Boklund, A., Toft, N., Halasa, T., 2018. Drivers for livestock-associated methicillin-resistant Staphylococcus aureus spread among Danish pig herds - A simulation study. Sci. Rep. 8:18962, 1-11. https://doi.org/10.1038/s41598-018-34951-1

Sørensen, A.I.V., Rosendal, T., Widgren, S., Halasa, T., 2018. Mechanistic modelling of interventions against spread of livestock-associated methicillin-resistant Staphylococcus aureus (LA-MRSA) within a Danish farrow-to-finish pig herd. PLoS One 13, 1-14. https://doi.org/10.1371/journal.pone.0200563

Sørensen, A.I.V., Toft, N., Boklund, A., Espinosa-gongora, C., Græsbøll, K., Larsen, J., Halasa, T., 2017. A mechanistic model for spread of livestock-associated methicillin-resistant Staphylococcus aureus (LAMRSA) within a pig herd. PLoS One 12, e0188429. https://doi.org/10.1371/journal.pone.0188429

Verhoeven, P.O., Grattard, F., Carricajo, A., Lucht, F., Cazorla, C., Garraud, O., Pozzetto, B., Berthelot, P., 2012. An algorithm based on one or two nasal samples is accurate to identify persistent nasal carriers of Staphylococcus aureus. Clin. Microbiol. Infect. 18, 551-557. https://doi.org/10.1111/j.14690691.2011.03611.x 


\section{Supplementary Materials}

638 Tables

639

640

641

642

643

644

645

646

647

648

649

650

651

652

653

654

655

656

657

658

659

660

661

S1 table. Parameterisation A: Sample distribution probabilities used for assigning load classes at different prevalences of positive animals.

S2 table. Parameterisation B and C: Initial load upon infection

Figures

S1 fig. Association between prevalence of LA-MRSA positive weaners within a batch and nasal LA-MRSA load in the weaners in the batch

S2 fig. Day-to-day variation in load carried by pigs

S3 fig. Convergence plots for the three different parameterisations

S4 fig. Semi-quantitative data used for validation of load distribution

S5 fig. Air levels in the gestation unit - effect of reduced transmission

S6 fig. The effect on the air concentration of LA-MRSA shedders in the different barn units, when every day a load reduction of one load class is conducted in a given barn unit.

Appendices

Appendix A: Transmission parameters

Appendix B: Transmission equations

Appendix C: Simulated interventions

Appendix D: Variance between iterations in load class distribution

Highlights:

- An agent-based simulation model for spread of LA-MRSA within a pig herd was built

- The model takes into account the amount LA-MRSA on the pigs and in the air

- The model enables simulation of the effect of interventions on exposure through air

- Three different parameterization methods was compared 
666

\section{CRediT Author Statement}

668 Anna Irene Vedel Sørensen: Conceptualization, Methodology, Formal analysis, Visualization, Writing 669 Original Draft, Julie Elvekjær Hansen: Data Curation, Writing - Review \& Editing, Tariq Halasa:

670 Conceptualization, Methodology, Writing - Review \& Editing.

671

672 Declarations of interest: None

673 